\title{
Illegitimacy, Infant Feeding Practices and Infant Survival in Sweden 1750-1950 A Regional Analysis
}

\author{
Anders Brändström, Sören Edvinsson and John Rogers
}

The general decline of mortality in Europe after 1750 constitutes one of the great puzzles of historical demography. We now have a vast amount of information on various aspects of the decline, although much of it has come into being in an ad hoc fashion. Some ten years ago Reher and Schofield pointed out in their review of the status of research on the European mortality decline, "it would only be a small exaggeration to say that our understanding of historical mortality patterns, and of their causes and implications, is still in its infancy." After a decade of further research their statement is still valid.

In the context of the Swedish demographic transition, infant mortality played a key role in the general decline in mortality. Deaths among children under one year of age contributed to almost 30 percent of the total number of deaths in the middle of the eighteenth century. By the middle of the nineteenth century the proportion of infant deaths had decreased to 22 percent and by the end of the century to 17 percent. By the middle of the twentieth century infant deaths constituted only 2.7 percent of all deaths. The decline of mortality observed in the model is thus, to a large extent, the result of the long and steady decrease in infant mortality (Figure 1). Infant mortality in Sweden during the second half of the eighteenth century fluctuated around 200 deaths per 1000 live births (200\%). After the first decade of the nineteenth century infant mortality declined steadily reaching 150 per thousand by the middle of the century. Rates dipped below 100 per thousand at the beginning of twentieth century and now constitute less than five infant deaths per thousand live births. This gradual decline was atypical in a European context, where child mortality often played a more central role. ${ }^{2}$

1 Roger Schofield and David Reher, "The Decline of Mortality in Europe," in The Decline of Mortality in Europe, eds. R. Schofield, D. Reher and A. Bideau (Oxford, 1991).

2 A. Perrenaud, "The mortality decline in a long-time perspective," in Pre-industrial 
Figure 1. Infant mortality rates in Sweden, 1750-1995.

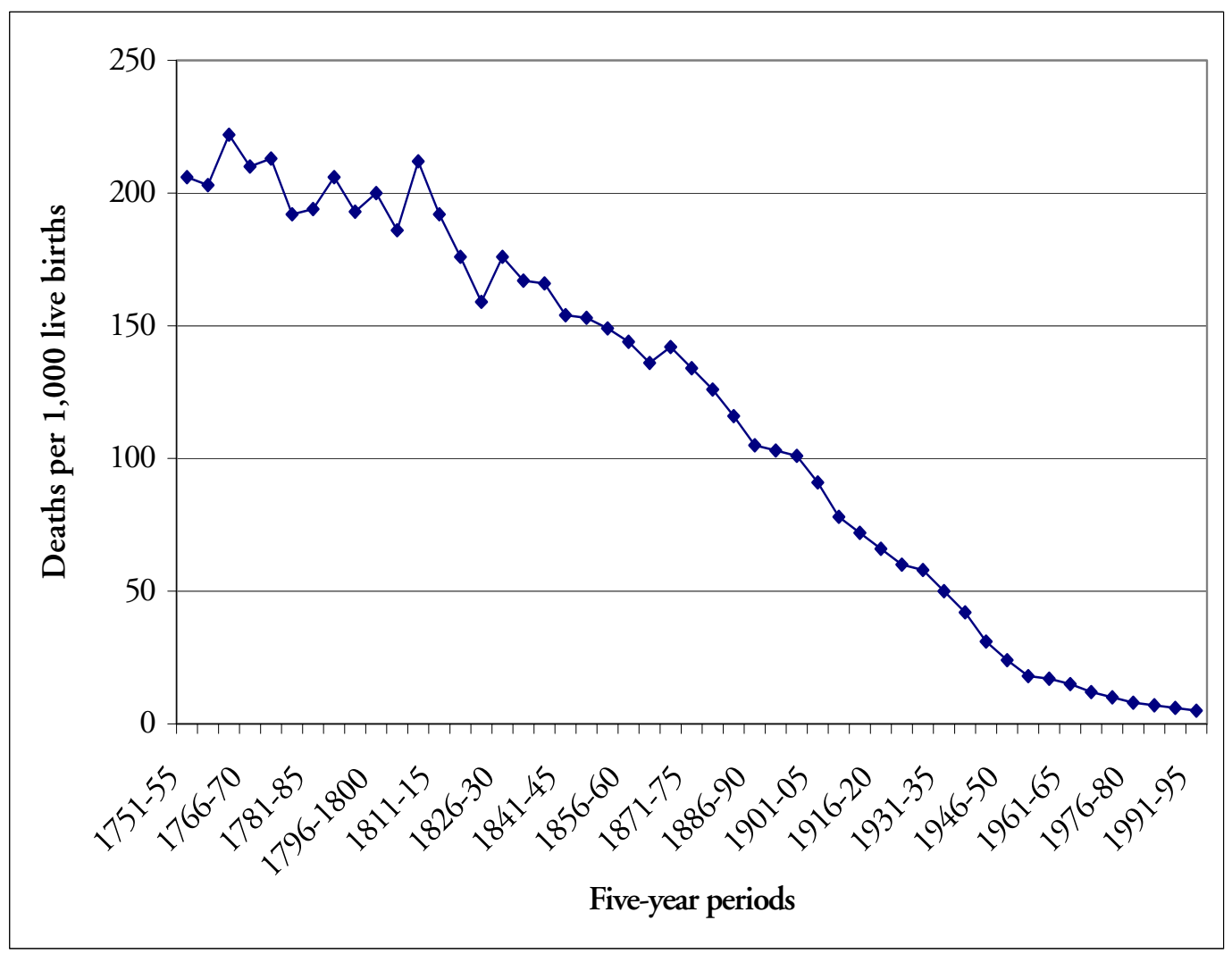

Source: Historical Statistics for Sweden. Part 1. Population (Stockholm 1969)

In Sweden attention has focused to a large part on the analysis of the causes of infant mortality in local areas for specific time periods. ${ }^{3}$ Attempts to generalize from

population change: The mortality decline and short-term population movements, eds. T. Bengtsson, G. Fridlizius and R. Ohlsson (Stockholm, 1984); Roger Schofield and David Reher, "The Decline of Mortality in Europe," in The Decline of Mortality in Europe, eds. R. Schofield, D. Reher and A. Bideau. (Oxford, 1991); The decline of infant and child mortality: The European Experience, 1750 1990, eds. C. A. Corsini and P. P. Viazzo (Florence, 1997).

3 There is a great deal of controversy concerning the causes of the decline in infant mortality in Sweden. See, for example, Christer Ahlberger and Christer Winberg, "Biologi, medvetet handlande och struktur," Historisk tidskrift (1987:3), 357-382; Ulla-Britt Lithell, "Amning och äktenskaplig fruktsamhet," Historisk tidskrift (1988:2), 231-238; Christer Winberg, "Amning, teorier och hypoteser," Historisk tidskrift (1988:2), 239-243. See also, Ingrid Eriksson and John Rogers, Rural Labor and Population Change. Social and Demographic Developments in East-central Sweden during the Nineteenth Century (Uppsala, 1978); Anders Brändström, "De kärlekslösa mödrarna" Spädbarnsdödligheten i Sverige under 1800-talet med särskild hänsyn till Nedertorneå (Umeå, 1984); Magdalena Bengtsson, Det hotade barnet. Tre generationers spädbarns- 
these local studies have provided explanations that tend to be time specific: for example the late eighteenth and early nineteenth century government information campaigns for improved childcare were thought to be important for the early decline in mortality. It has also been suggested that public health measures in the late nineteenth century and infra-structural improvements in health care in the twentieth century positively influenced the survival of children. The results from these local studies indicate that more work must be done on a regional analysis of infant mortality and that this must be done in a more systematic fashion.

The purpose of this study is to examine regional variations in infant mortality and how these were related to the improvements in the survival of infants. ${ }^{4}$ Were there distinct regional differences in infant mortality during the early nineteenth century, that is, at the outset of the decline of infant mortality? Did these patterns change as mortality declined? One of the most important factors influencing levels of infant mortality is related to infant feeding practices, in particular breast-feeding. Are variations in the frequency of breast-feeding related to regional variations in infant mortality? Illegitimate infant mortality has been shown to be consistently higher than legitimate infant mortality. Were there variations in illegitimate infant mortality and did these change as infant mortality declined?

\section{Provincial Level Data on Infant Mortality}

If we consider patterns and trends on a provincial level during the period of the demographic transition, we find that there was a significant amount of variation in infant mortality. ${ }^{5}$ The sources include both published and unpublished data on a provincial level (län) in Sweden from 1811 to $1972 .{ }^{5}$ Boundary changes, while they did occur, were generally small and do not affect levels or trends in the comparisons. Because of the varying nature of the sources, infant mortality rates for both

och barnadödlighet i 1800-talets Linköping. (Linköping, 1996); For a review of research on infant and child mortality in Sweden, see, John Rogers, "Nordic Family History: Themes and Issues, Old and New," Journal of Family History, $18: 4$ (1993), 291-214.

4 The Swedish project is supported by the Bank of Sweden Tercentenary Foundation. This project "Toward a better society" treats numerous aspects of the decline of infant mortality in Sweden, such as regionality, fertility, illegitimacy, social and economic conditions, family relations, environmental aspects, etc. In order to be able to compare results, we have limited the analyses in this paper to three main aspects - regionality, child feeding practices and illegitimacy.

5 The Swedish administrative unit län is generally translated as county but province is a more appropriate term. For listing of the provinces and their location, see Appendix 1. 
Map 1. Infant mortality rates (per 1,000 live births) for the provinces of Sweden, $1811-1815$.

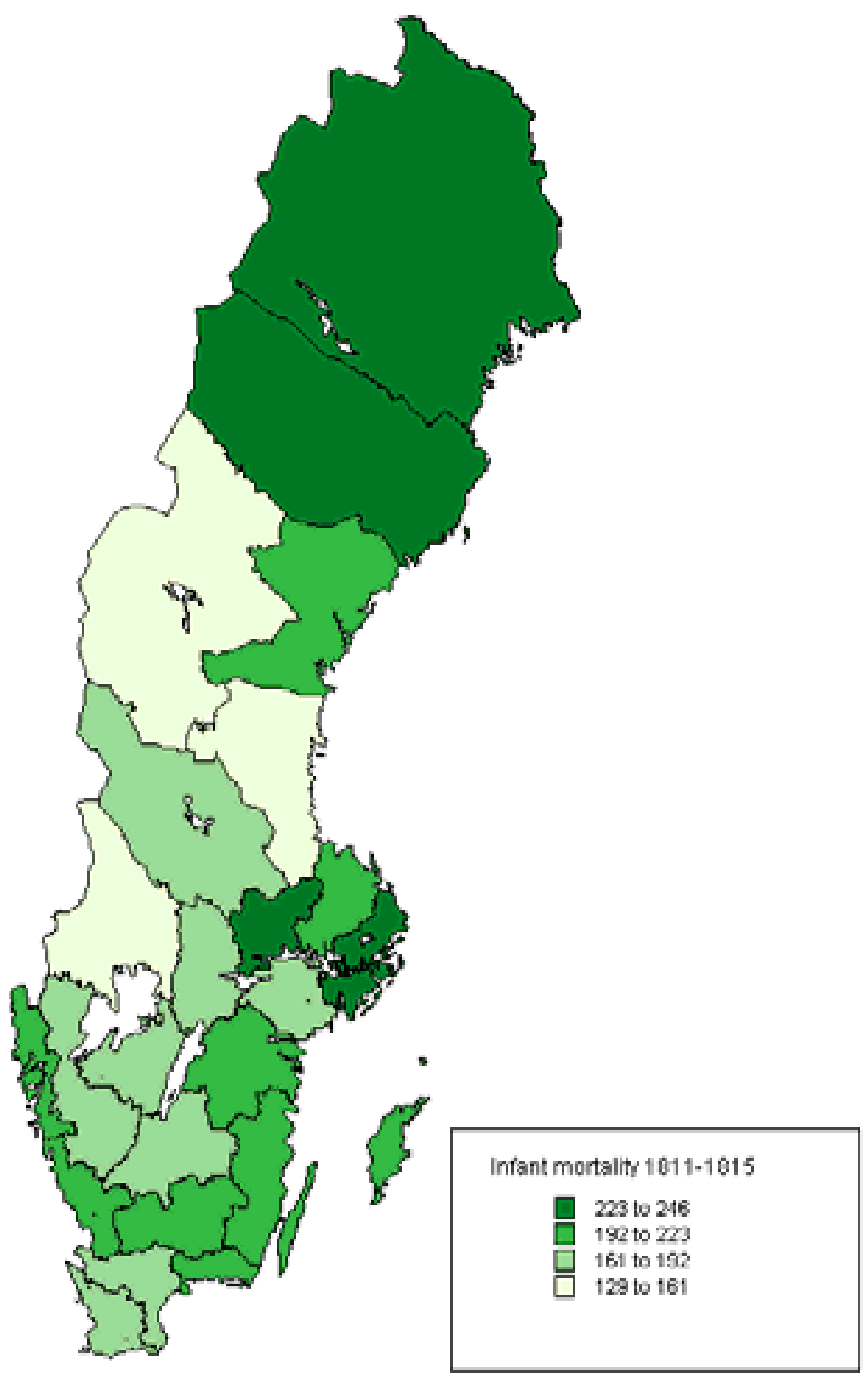

Source: Tabellverket. Provincial statistics. National Archives. 
Map 2. Infant mortality rates (per 1,000 live births) for Swedish provinces, 18461850.

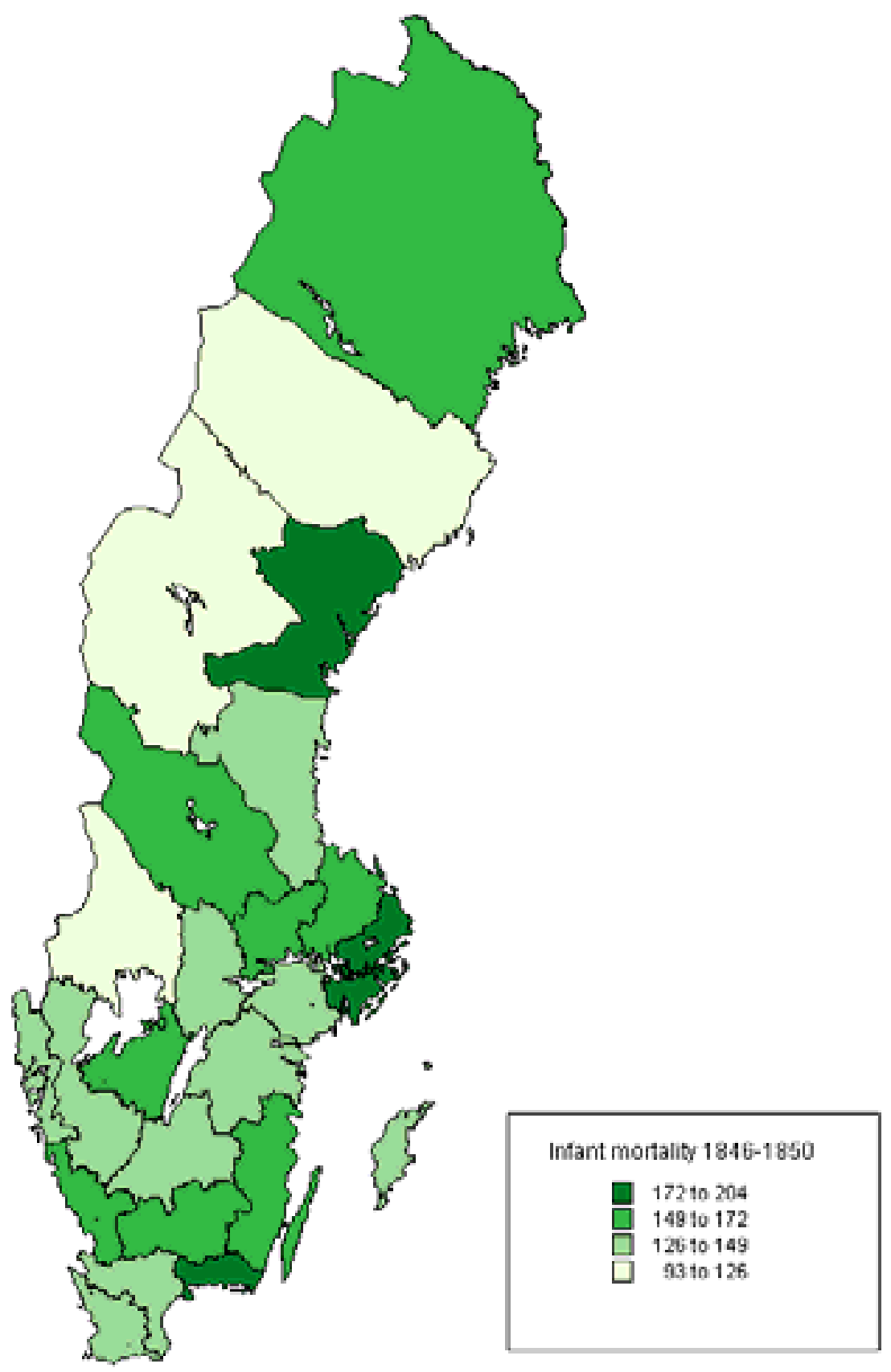

Source: Tabellverket. Provincial statistics. National Archives. 
sexes combined will be used. The maps are constructed so that the scale increase or or decreases with one unit of standard deviation from the mean of provinces.

At the beginning of the nineteenth century (Map 1) high rates of infant mortality are observable in the far north, in the vicinity of the capital, Stockholm, and in a ushaped band of provinces stretching along the west coast through the southern part of the country to the east coast. During the first half of the nineteenth century infant mortality declined, with the highest rates dropping from 246 to 204 per thousand and the lowest from 129 to 93 per thousand. By mid-century (Map 2) regions of high mortality in the north and south had been reduced somewhat, and the area of high mortality originating near the capital had expanded westward. The provinces of Jämtland and Värmland (see Appendix 1) had low rates at both these points in time.

There was no clear relationship with population density during the period. Urban infant mortality rates were significantly higher than rural rates, but because the country was so little urbanized during this period, that fact is not reflected in the figures for the provinces. Only some ten percent of the population resided in urban areas, and the capital, with a population of about 93,000 in 1850, was the only city comparable in size to other major European cities. From the middle of the nineteenth to the middle of the twentieth century regional patterns of infant mortality changed as levels declined considerably (Maps 3 and 4). Again, there was no clear relationship with either population density or level of urbanization. However, national level figures show that in the 1920s and 1930s a shift in urban-rural differentials took place. Urban infant mortality is now lower than rural. The earlier relationship between urbanization and therefore high population density and high infant mortality is reversed. A possible explanation is that the medical infrastructure expanded more rapidly in urban areas. After 1950 mortality levels and the difference between the highest and lowest rates continued to diminish. The more densely populated areas, which also coincided with the most urbanized areas, had the lowest levels of infant mortality. The only consistent pattern over a longer period of time is that the northernmost provinces registered the highest rates.

Another way of illustrating these regional trends is with contour shape maps. Figure 2 shows the development of indexed infant mortality for eleven provinces between 1811 and 1972. The index is calculated by dividing infant mortality by the national average rate, 1811-1815. Clearly there were large regional variations in development over time. Jämtland had very low infant mortality already during the eighteenth century. During the first half of the nineteenth century the province remained well under the national average; 1811-1815 infant mortality in the province was 60-80 percent of the national average and in the years 1831-1835 about half. However, during the last half of the century the relative position of Jämtland remained unchanged. By the end of the nineteenth century infant mortality in several other provinces, such as Värmland and Skaraborg, improved, 
Map 3. Infant mortality rates (per 1,000 live births) for Swedish provinces, 18991902.

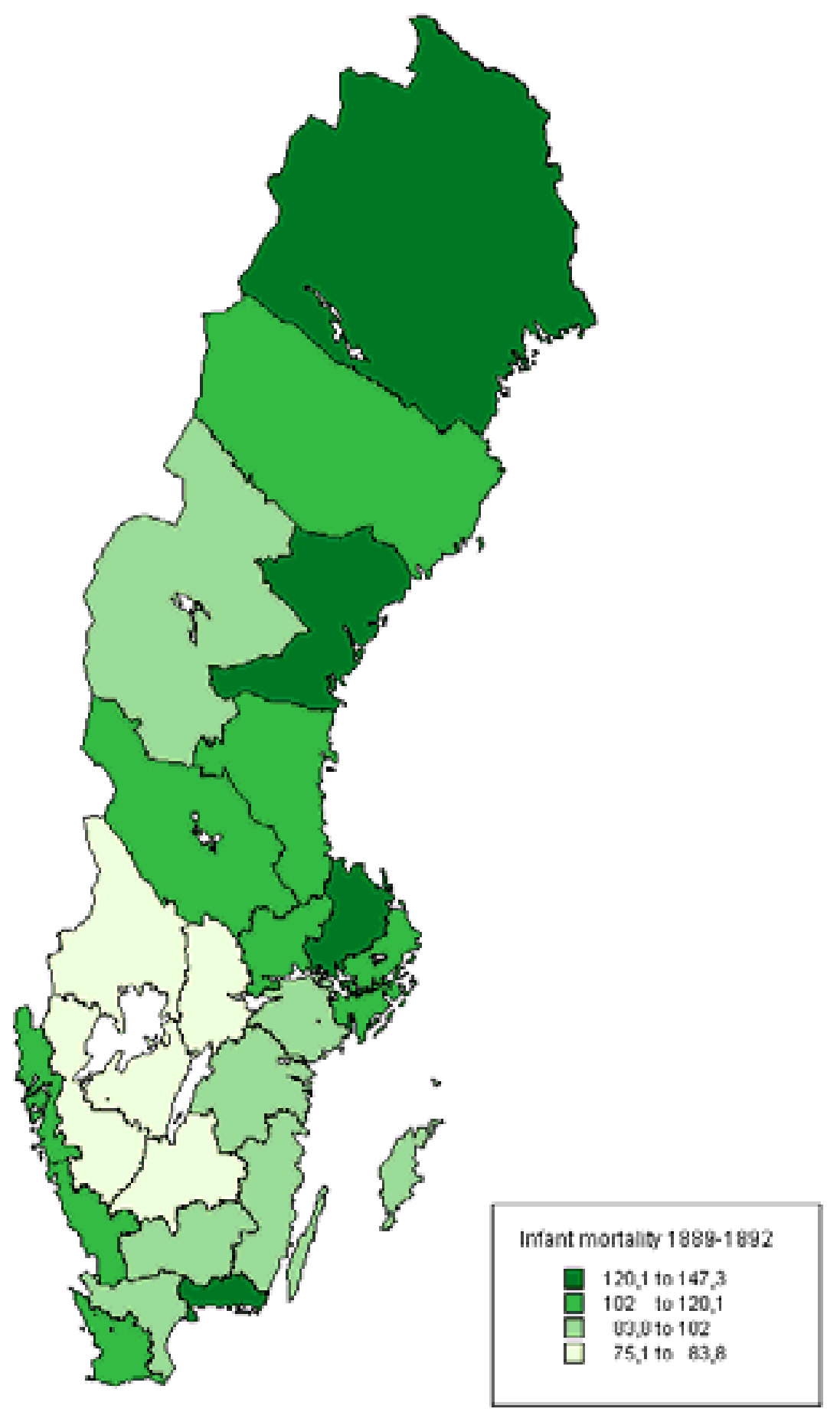

Source: Erland Hofsten and Hans Lundström, Swedish Population History. Main Trends from 1750 to 1970 (Stockholm, 1976). 
Map 4. Infant mortality rates (per 1,000 live births) for Swedish provinces, 19491952.

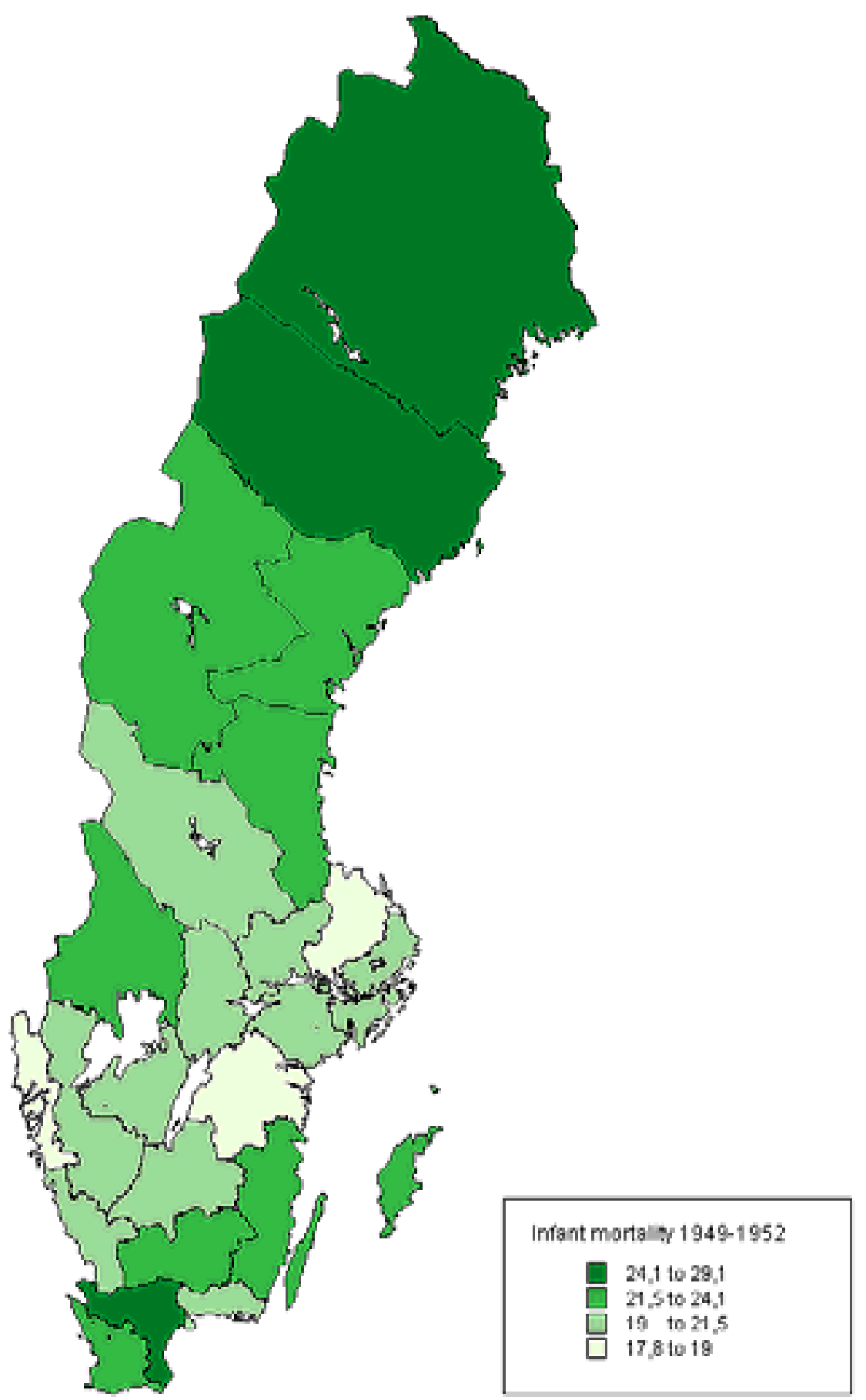

Source: Erland Hofsten and Hans Lundström, Swedish Population History. Main Trends from 1750 to 1970 (Stockholm, 1976). 
Figure 2. Indexed infant mortality for eleven Swedish provinces, 1811-1972. National average $1811-1815=100$.

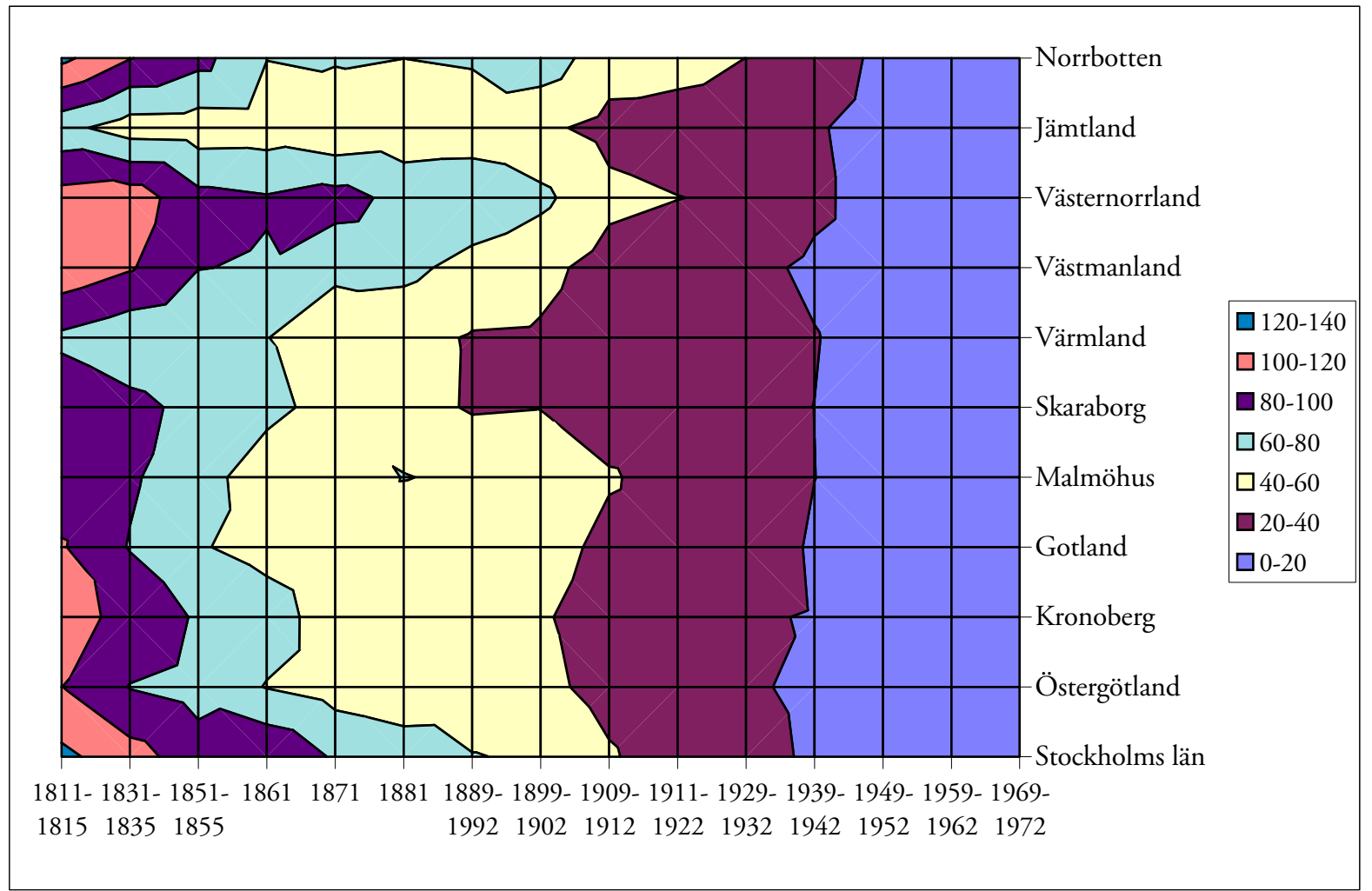

Source: Tabellverket. Provincial statistics. National Archives; Erland Hofsten and Hans Lundström, Swedish Population History. Main Trends from 1750 to 1970 (Stockholm, 1976).

reaching the same 20-40 percent level as Jämtland. In contrast to Jämtland developments in the adjacent province of Västernorrland were strikingly different. Infant mortality was above the national average in 1811-1815 with declines coming very late in Västernorrland. It was not until the early twentieth century that Västernorrland reached the same level that Jämtland had experienced in 1831-1835. A similar slow development also characterised the provinces of Stockholm and Norrbotten. In the latter, Sweden's northernmost province, infant mortality did not fall below 40 percent of the national index until 1929-1932. With the exception of Norrbotten, regional differences on a larger scale ceased to exist after 1911-1922.

The fact that there is no apparent relationship between population density and urbanization and regional variations in infant mortality indicates that specific regional factors were affecting the survival of infants and that these factors varied from place to place and over time. A study of infant mortality on the parish level in the province of Västerbotten in the 1860s by the physician and statistician Johan Hellstenius clearly revealed one of the major problems in working with provincial level data. Hellstenius found that parishes with large Saami (Lapp) populations had higher infant mortality rates and that the populations of districts where there were 
iron works had lower rates than the average for the province. ${ }^{6}$ The provinces in Sweden are generally so large that highly divergent economic and social structures as well as distinct cultural areas may be found in one and the same province.

\section{Parish Level Data on Infant Mortality}

While provincial level data indicate that the story behind the gradual decline in infant mortality on a national level in nineteenth century Sweden is complicated, it is clear that even these figures conceal considerable variations in both levels and trends. To address this problem we need to create regions based on infant mortality rates that are not delimited by larger administrative boundaries, but are based on parish data. A usable source material for this purpose is parish level data compiled by Tabellverket containing demographic information on fertility and mortality on an annual basis from 1749 to 1859 . Population data is available for various years (annually between 1749-1751, every third year from 1754, and every fifth year from 1775). The material is now available in digitalized form at the Demographic Data Base at Umeå University, Sweden. The data sets in this article include information on approximately 2,400 parishes. ${ }^{7}$ Data on two periods, 1803-1807 and 1848-1852 (later referred to as 1805 and 1850), are available. The 1805 analysis falls within the pre-transitional period in Sweden, while the 1850 study reflects a phase when infant mortality had significantly decreased.

In this study we have created regions of high, moderate, and low infant mortality based on parish data. The maps are constructed so that the data values break one standard deviation above or below the mean. The rates produced are for both sexes combined. Infant mortality rates are calculated by dividing the number of infant deaths in a given period by the number of live births during that same

6 Johan Hellstenius, "Barnadödligheten i Västernorrlands och Jemtlands län, 18601882," Statistisk tidskrift, 73 (1884), 153-168.

7 The source material consists of forms sent in by the parish ministers to Tabellverket. A number of those forms are missing, and others include information on more than one parish. For the first period, we lack information for 358 parishes (14.7\%) and for the second period, 264 parishes $(10.8 \%)$. The problem of the missing data was not systematic, but it did affect some parts of the country more than others. In northern Sweden, the parishes tended to be large and sparsely populated, and the effect of missing data in such parishes is more pronounced when the results are presented in cartographic form. 
Map 5. Infant mortality rates (per 1,000 live births) for regions created using parish-level data, 1803-1807.

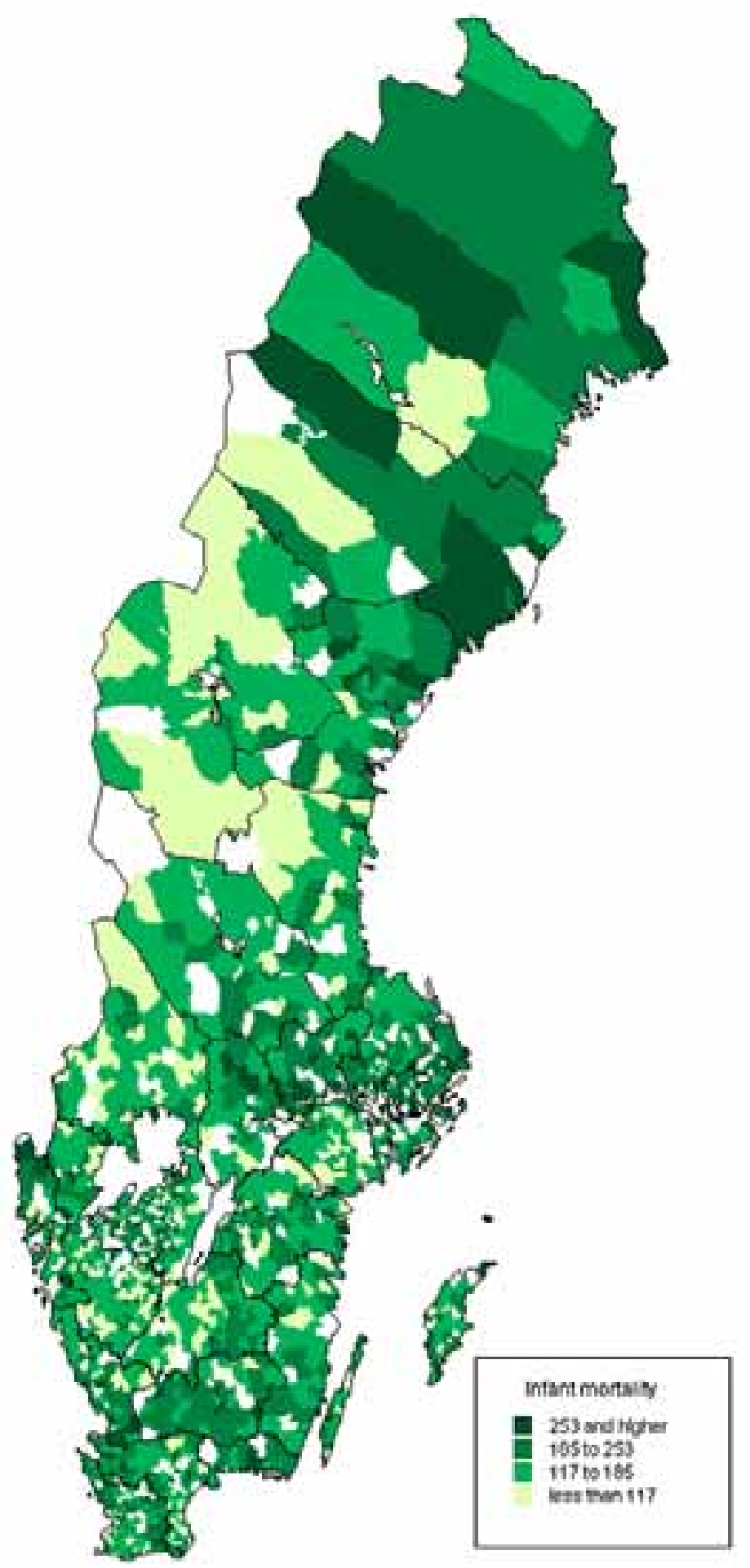

Source: Tabellverket. Parish statistics, The Demographic Data Base, Umeå University 
Map 6. Infant mortality rates (per 1,000 live births) for regions created using parish-level data, 1848-1852.

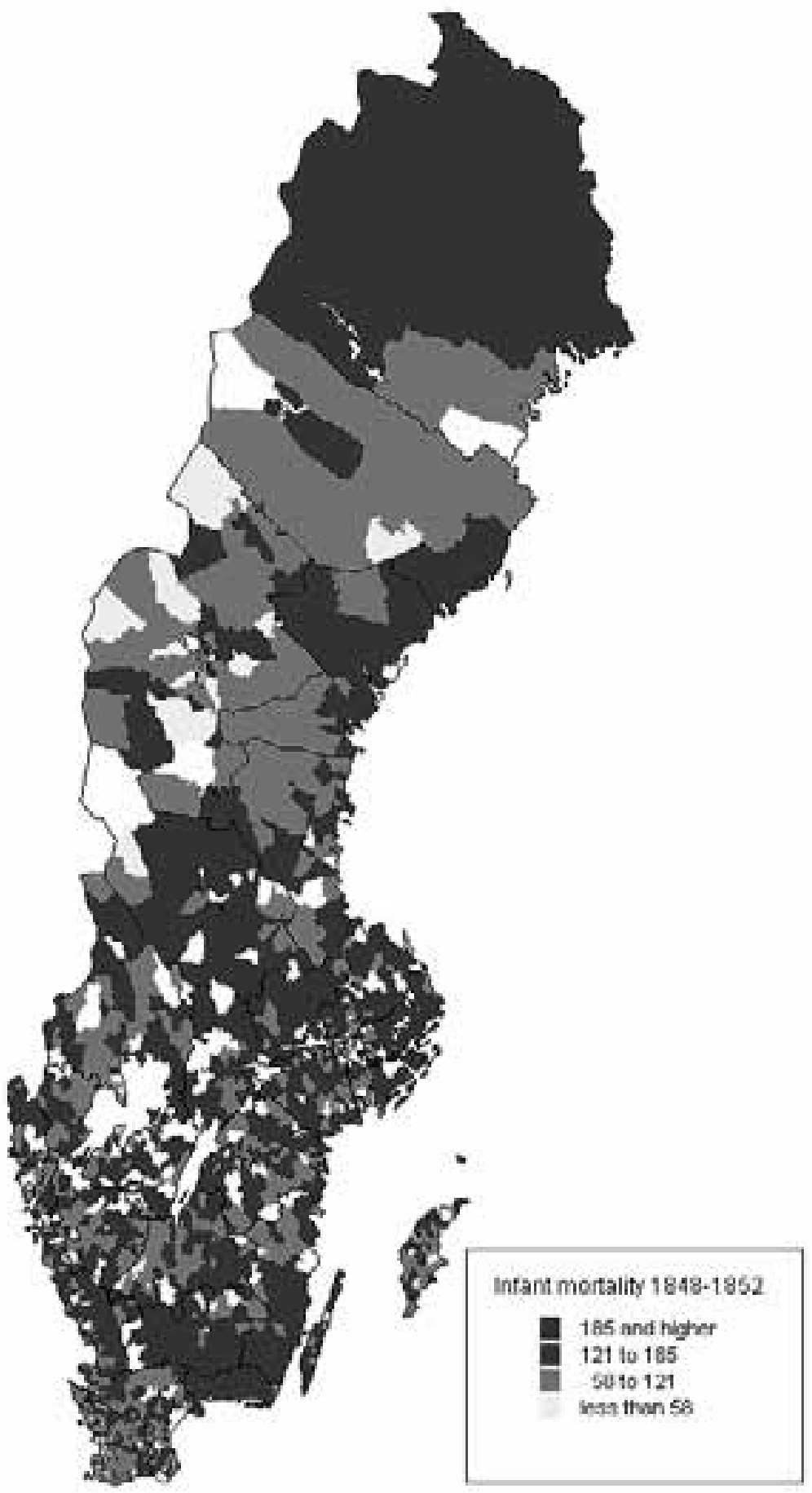

Source: Tabellverket. Parish statistics, The Demographic Data Base, Umeå University. 
period. ${ }^{8}$ Rates are computed for five-year periods surrounding those years with available population figures.'

The distribution of high, moderate and low infant mortality observable in the maps using provincial data (Maps 1 and 2) is reflected in the maps based on parish data (Maps 5 and 6). The parish level data also changes between the two time points observable on the provincial level. Comparing Maps 1 and 2 with Maps 5 and 6, we see that northernmost Sweden had generally high levels of infant mortality, whereas the provinces of Jämtland and Värmland exhibited low levels both at the beginning and in the middle of the nineteenth century. The expansion of the high mortality region westward from the capital, Stockholm, is also apparent in the parish-based maps. The contracting of the u-shaped band of high mortality provinces is, however, not evident in the maps using parish level data. Instead of a $\mathrm{u}$-shaped region we find a flat band of parishes with high infant mortality in the south stretching from coast to coast. By mid-century the parish-based regions of high infant mortality tended to be more concentrated on the east coast. Furthermore, the regional distribution in some parts of the country changed markedly. However, in other parts of the country, for instance in northernmost Sweden, along the coast of the provinces of Västernorrland and southern Västerbotten, in the plains region northwest of Stockholm, and in southeastern Sweden, we observe relative stability.

Mapping parish level data has shown that the provincial regional patterns include a great deal of variation. All of the regions, whether they had high, low, or moderate rates, include smaller areas (larger than a single parish) with divergent levels of infant mortality. The fact that areas with low infant mortality located in regions with high or moderate rates display similar low levels at both points in time indicates that we are not picking up traces of random fluctuation. This is also true for the other combinations (i.e., high mortality areas in moderate or low infant mortality regions and moderate areas in high and low level regions).

In the context of Swedish research on infant mortality a number of important points can be made. In general, the mix of high, moderate, and low is apparent

8 The statistical tables that form the basis for the database used here do not allow the compilation of infant mortality rates following all individual births for one year in a given period. The birth and death registers on which the statistical tables are based, however, do allow rates to be calculated in that manner. A comparison of the two methods showed that discrepancies were not large, except for parishes with very small numbers of births. Anders Brändström, Sören Edvinsson and John Rogers, "Infant Mortality in Sweden. Creating Regions from NineteenthCentury Parish Data," Historical Methods, 33:2 (2000), 105-114.

9 Because some of the original tables are missing or damaged, calculations for a small number of parishes are based on periods of less than five years. 
nearly everywhere, a fact missed by earlier research. For example, the province of Jämtland, which has continually produced the lowest rates in the country, is divided into areas of high, moderate, and low mortality. This makes it necessary to modify the earlier attempts at explaining the low rates, for example, by arguing that the province was isolated and thus less susceptible to infectious diseases. Another point of interest is the fact that in the plains area south of the capital in east-central Sweden and in the plains area in Skåne in southern Sweden (provinces of Kristianstad and Malmöhus) several smaller regions with low rates of infant mortality are observable. This is all the more remarkable since both areas were densely populated, on the main routes of communication, and contained no significant natural barriers such as large forests or lakes to separate different areas.

\section{Infant Feeding Practices and Infant Mortality}

Studies of infant mortality in both historical and modern populations have shown that one of the most important factors affecting levels of infant mortality is the manner in which babies were fed. It is clear from these various studies that artificially fed infants were more likely to die during their first year of life than infants that were breast-fed. Breast-feeding increases the chances of survival in several ways. Breast milk provides the necessary nutritional needs of infants, particularly during the first six months after birth. Children artificially fed, on the other hand, run a higher risk of being under-nourished and with malnutrition the risk for infections increases significantly. Breast-feeding also helps build up the immune system of a newborn baby. Through breast-feeding, antibodies against infectious diseases are transferred from mother to child. Artificially fed babies are more likely to come into contact with contaminated food, thus exposing them to infectious diseases. This is particularly a problem in areas where sanitary and hygienic conditions are of a low standard. Breast-feeding also functions as a contraceptive measure, prolonging the length of birth intervals. Shorter birth intervals, the result of children being artificially fed and dying as infants, also increase the chances that the next child will die young. Research has shown a clear association between shorter birth intervals and higher rates of infant mortality. ${ }^{10}$ Clearly, variations in breast-feeding patterns influence levels of infant mortality and, to some extent, explain observed regional differences in levels of infant mortality.

Historical evidence on breast-feeding patterns is scarce and often beset with problems of interpretation. In the second half of the nineteenth century the

10 Katherine A. Lynch and Joel B. Greenhouse, "Risk Factors for Infant Mortality in Nineteenth-Century Sweden," Population Studies, 48:1 (1994), 117-133. 
Map 7. Breast-feeding in the districts of Swedish provincial physicians 1889-1874.

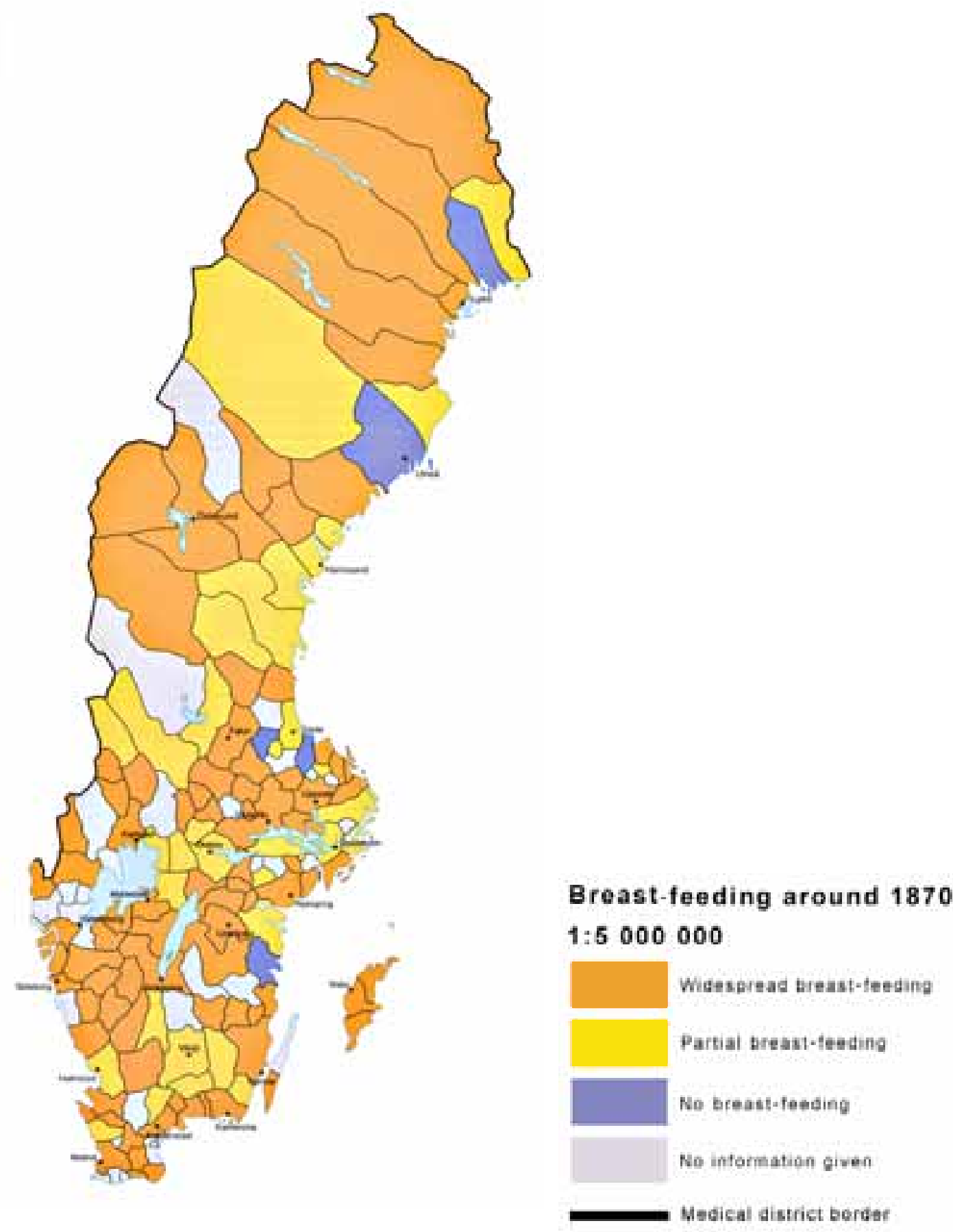

Source: Anders Brändström and Sören Edvinsson, "From the past to the present - dramatic improvements in public health," in National Atlas of Sweden. Public Health and Health Care, Special eds. Gudrun Lindberg and Måns Rosén (Uppsala, 2000). 
National Board of Health (Sundhetcollegium) conducted a survey among stateemployed medical officers on infant feeding practices. The study was carried out in order to evaluate the effectiveness of various governmental campaigns promoting breast-feeding. Doctors were urged to make general statements such as "In my district all children are breast-fed" or "Women in the district do not breast-feed." No exact measure of the frequency of breast-feeding was provided in the survey. Map 7 shows the result of the survey. Although several source critical problems are associated with the survey, it does provide information on how the different districts were related to one another with regard to breast-feeding patterns.

If we compare variations in breast-feeding (Map 7) with regional variations in infant mortality (Map 6), we find no clear-cut association between the two. In the northernmost part of the country, the province of Norrbotten, breast-feeding was widespread and was associated with high levels infant mortality. The same is true for the province of Blekinge in the southeastern part of the country. On the other hand, the province of Jämtland in the middle of the country on the Norwegian border is an example of the expected association, i.e. low infant mortality associated with widespread breast-feeding. Another region where the expected association appears is along the coast in the northeastern part of the country in the province of Västerbotten. Here high infant mortality is associated with artificial feeding practices.

In 1914 the government attempted a new survey based on a questionnaire sent out to approximately 2,500 state-employed midwives. Because the questionnaire only required the midwives to answer in very general terms, similar to the survey of the doctors in 1869, the results are difficult to interpret. Both studies, however, indicate that there was a significant amount of variation in breast-feeding in Sweden during the nineteenth and early twentieth century.

Historical studies of infant mortality have shown that several factors influenced the relationship between breast-feeding and child survival. One of the more important aspects was related to the socio-economic position of the family. Local studies from mainly nineteenth century agrarian environments provide contradictory results. In some areas the better-situated had the expected lower infant mortality compared to those futher down on the social scale. In other areas infant mortality was lower among the landless than among the land-owning peasantry (Appendix 2).

From these local studies a number of points about variations in breast-feeding can be made. Mothers in families that were better off generally had more time to nurse their children. Although the workload of women among the land-owning peasantry was often significant, such families generally had sufficient resources to allow mothers to care for small children. Servant girls could be employed or other family members could help out. In families with limited resources, the need for a woman to contribute to the family's income more often came into conflict with childcare. Relatives generally did not reside in such households. Artificial feeding 
provided an alternative. Such practices, such as providing cow's milk in "feeding horns," often proved detrimental to the infant's health. However, several other factors may also have influenced feeding practices. In some areas it appears that the poorer families were so poor that the only available food source for infants was breast milk, which in turn resulted in better child survival. In this case the beneficial effects of breast-feeding were the result of poverty. In areas with cottage industries and in industries employing women, breast-feeding also tended to be limited.

In other areas cultural factors played an important role. Traditional feeding practices, such as the early introduction of solid foods, often meant that breastfeeding diminished or was stopped altogether. Often the nutritional value of food given to small infants was deficient. The practice of chewing food before giving it to an infant is associated with the transfer of various bacteria that produced deadly infections. In such areas even the better-situated families followed such traditional feeding practices. The key factors affecting breast-feeding appear to have been related to cultural considerations, in particular long-standing traditions, and to the need for a woman's labor on the household level and/or her participation in the labor force. There is, as such, no straightforward association between regional differences and variations in socio-economic structures. Regions dominated by, for example, well-to-do peasants could have high, moderate or low levels of infant mortality depending on how important cultural factors such as traditional feeding practices tended to be.

\section{Illegitimacy and Infant Mortality}

The level of illegitimacy must be considered in any attempt to explain regional differences in infant mortality. Historically, illegitimate infant mortality has always been higher than legitimate infant mortality. The illegitimacy ratio increased in most European countries during the nineteenth century. In Sweden, approximately 62 out of every 1,000 live births (62\%o) were illegitimate, 1811-20. By 1851-60 their numbers had increased to 90 per thousand, and by the turn of the century, to 110 per thousand. Illegitimacy was mainly an urban phenomenon in Sweden with rates in towns often exceeding 200 per thousand. Even though the countryside displayed comparatively lower ratios, illegitimacy was still considered a large problem, both by medical men and, of course, church officials.

Several explanations for this increase in illegitimacy during the nineteenth century have been advanced. According to Edward Shorter, there is a relationship between economic change, mainly the introduction of capitalism, and an increase in illegitimacy. Women from the lower classes were drawn into a new monetary economy, which allowed them a greater degree of personal freedom, including sex- 
ual freedom. They no longer had to depend on their parents or a husband for support. ${ }^{11}$ Shorter has received a great deal of criticism, mainly because he has presented little empirical evidence supporting his assumptions. Tilly, Scott and Cohen find that women's salaries were so low that they could hardly have contributed to their economic independence. Instead, they suggest that the increase in illegitimacy was the result of traditional values colliding with new norms in a rapidly transforming society. ${ }^{12}$

Peter Laslett has put forward a completely different explanation, arguing that the observed increase in illegitimacy was mainly due to the emergence of a subculture within the lower classes of society. Among these classes "official" social norms were generally viewed with suspicion. With little to gain from society came also the notion that there was nothing to gain from following the rules and norms of that society. Restrained sexuality was one of these norms. Naturally, belonging to the lower social classes did not necessarily lead to a promiscuous life, but many found an identity in a "deviant" way of life. Therefore, an increase in illegitimate births was not an effect of an increase in the number of women that gave birth to these children, but instead the result of women from specific segments of society giving birth to more illegitimate children. ${ }^{13}$

The Swedish ethnologist Jonas Frykman reached a conclusion similar to Shorter concerning the rise of illegitimacy in Sweden. Frykman interpreted the increase as the result of new ideas associated with the development of capitalism clashing with old social norms. Traditional values upheld by the church played a less significant role in the changing economy of the late nineteenth century. Instead, emotions came to play an increasing role in the selection of marriage partners. Both women and men experienced a new kind of freedom when they were no longer dependent upon inheriting a farm for their existence. ${ }^{14}$ In a rapidly changing society, old traditions such as bundling, collided with increased geographical mobility. According to Orvar Löfgren, bundling was an almost institutionalized form of social interaction between young, unmarried men and women. They met in situations that were potentially very sexual, but social norms and Christian values kept restraints on the couple. If a young woman happened to become pregnant, she could still count on marriage. ${ }^{15}$ However, when social control was weakened and geographical mobility

11 Edward Shorter, "Female emancipation, birth control and fertility," American Historical Review, 78:3 (1973), 612.

12 Louise Tilly, Joan Scott and Miriam Cohen, "Women's Work and European Fertility Patterns," Journal of Interdisciplinary History (1976), 461.

13 Peter Laslett, Bastardy and its Comparative History (London, 1980), 217.

14 Jonas Frykman, "Sexual intercourse and social norms," Etnologia Scandinavica (1975).

15 Orvar Löfgren, "Från nattfrieri till tonårskultur," Fataburen (1969). See also Michael 
Figure 3. Infant mortality among legitimate and illegitimate children in Sweden 1801-1900. Deaths per 1,000 live births, 10 years averages.

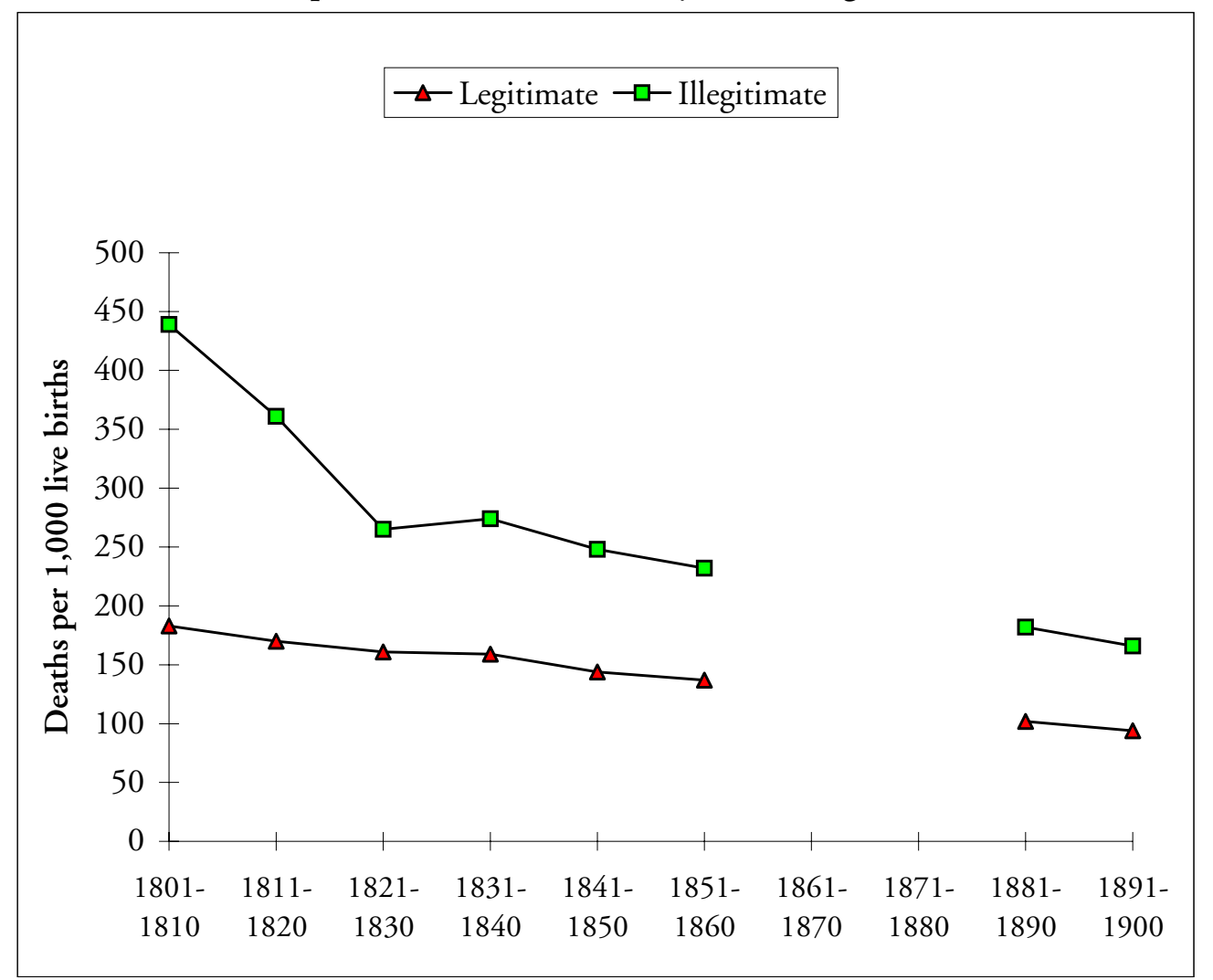

Source: Historical statistics for Sweden. Part 1. Population (Stockholm 1969), Tab. 41. The missing data indicates that no national data exists.

increased, traditional bundling resulted in a rapid increase in illegitimate births. ${ }^{16}$ In the eyes of the Swedish Lutheran Church the mother of an illegitimate child was not "pure" and could not take part in normal religious activities. She had to be purified according to the church law of 1686. Initially, the purification process was public. The unwed mother had to face the parishioners in the church, admit her sins and receive forgiveness. This was converted into a private rite in 1741 , the unwed mother being compelled to face the minister alone and admit her sins. Mercantilist Sweden was alarmed by the high death rates among illegitimate infants, who were potential contributors to the wealth of the nation. It was hoped that a change in the church law would lessen the social stigma of an illegitimate birth and decrease risks to the child, thereby increasing the population. Purification was

Mitterauer, Ledige Mütter. Zur Geschichte unehelicher Geburten in Europa (München, 1983) who discusses the role of bundling as part of a wider northern European culture.

16 Jonas Frykman, Horan i bondesambället (Lund, 1977). 
Map 8. Illegitimate infant mortality in Swedish provinces, 1811-1813, per 1,000 live births.

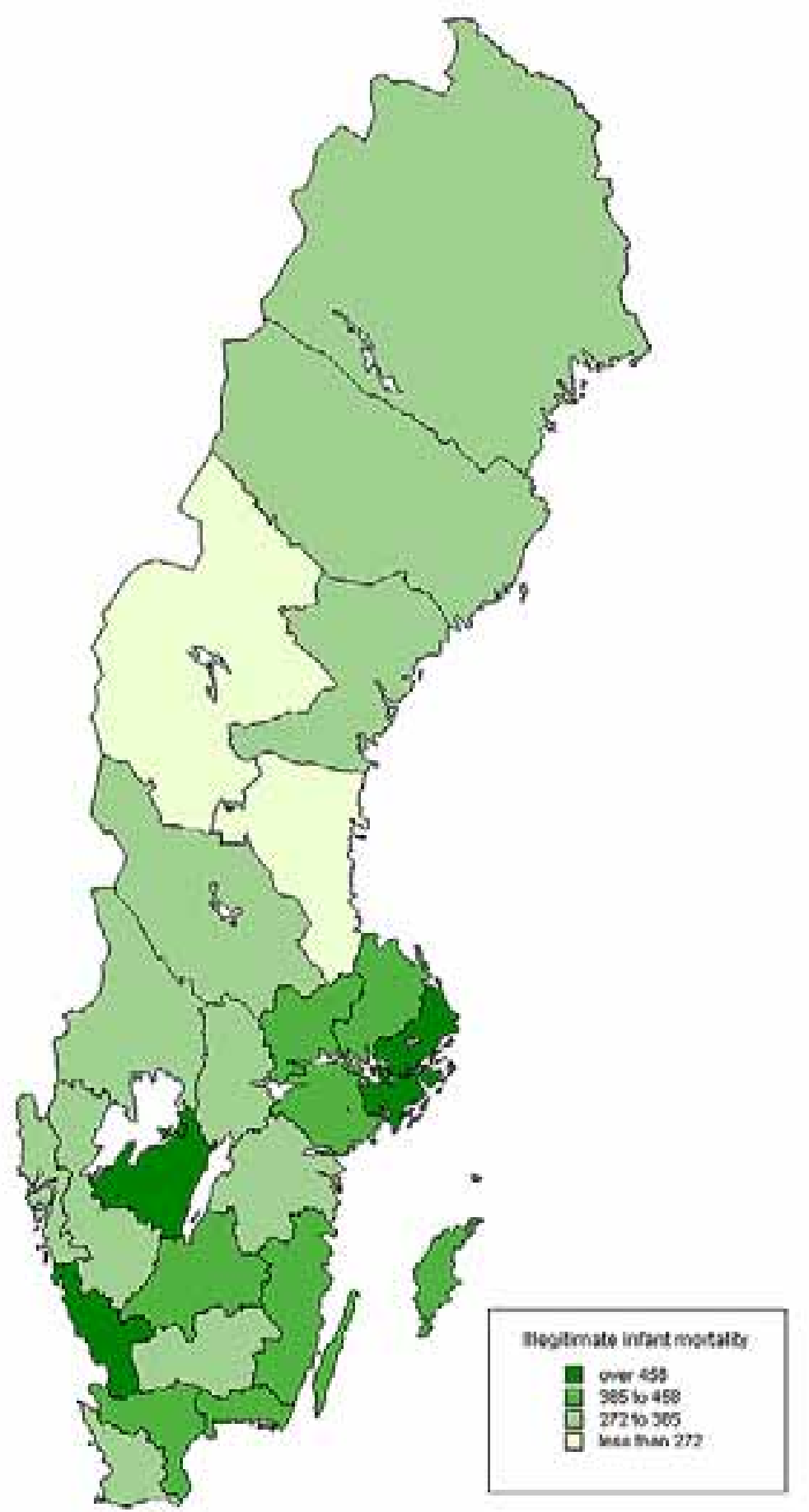

Source: Tabellverket. Provincial statistics. National Archives. 
officially abolished in 1855 , but the practice continued on the local level for several decades.

Illegitimacy was also a crime according to a 1734 statue. Punishment was usually a fine to be paid by the man - if his guilt could be proven in court. The law was changed in 1864 so that cases of illegitimacy could only be brought to court if the woman pressed charges against the presumed father. 'From 1865 onwards, illegitimacy was no longer considered a crime by the state church and the Swedish government. However, social norms condemning sex outside marriage continued to exist despite the legal changes. Differences in infant mortality between legitimate and illegitimate children were still considerable as can be seen in Figure 3, which would indicate that, while the situation for single mothers improved in some areas, it remained much the same in others.

On a regional level illegitimate infant mortality differed considerably, with the highest rates in the provinces around Stockholm and in the south (Map 8). A reasonable hypothesis is that a low rate of illegitimacy would result in relatively high levels of illegitimate infant mortality. In areas where illegitimate births were common, they would be regarded with less suspicion and lead to less stigmatization, which in turn would have resulted in lower levels of illegitimate mortality. For instance, the northern province of Västerbotten was strongly influenced by a pietistic religious movement and relatively few children were born out of wedlock. Illegitimate infant mortality should have been high there. In Stockholm, on the other hand, the illegitimacy ratio was an astonishing 358.4 per thousand births at the beginning of the nineteenth century. Stockholm should therefore have provided the most tolerant environment for children born out of wedlock. However, if we compare maps where we have calculated excess illegitimate infant mortality (i.e. illegitimate infant mortality divided by legitimate infant mortality x 100), we find no support for the hypothesis (Maps 9a-b). No correlation was found when the data was analyzed statistically.

In comparison to the first period, the relative level of illegitimate infant mortality increased in northern Sweden and also on the west coast, particularly in the province of Göteborg and Bohus. The area around Stockholm continued to be characterized by high illegitimate infant mortality (Map 10). If we consider excess illegitimate infant mortality for rural Sweden in 1901-1910 (Maps 11a-b) we find a pattern quite similar to the one in 1811-1813. Low levels are again found in the north and high levels around Stockholm and sections of the west coast, indicating that illegitimacy may to a large degree have been culturally rooted. Again, we find no correlation between excess illegitimate infant mortality and the proportion of

1 Katarina Andersson, "Ogifta mödrar i Östersund under 1800-talet," (Unpublished paper, Department of History, Umeå University, 1993). 
Map 9a. Excess illegitimate infant mortality, Swedish provinces 1811-1813. Illegitimate infant mortality/legitimate infant mortality*100

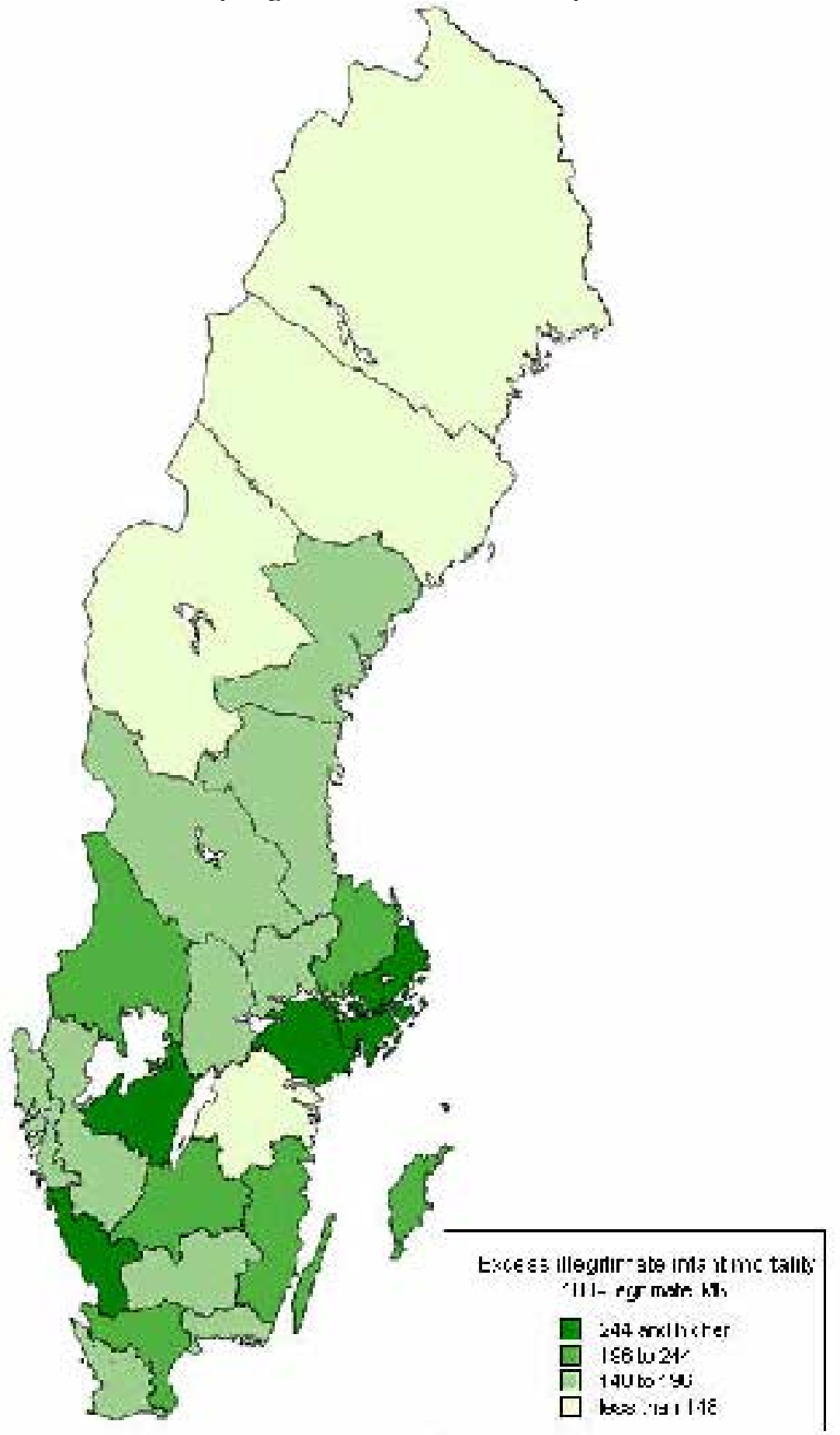

Source: Tabellverket. Provincial statistics. National Archives. 
Map 9b. Illegitimacy in Swedish provinces, 1811-1813. Illegitimate births/all births*100.

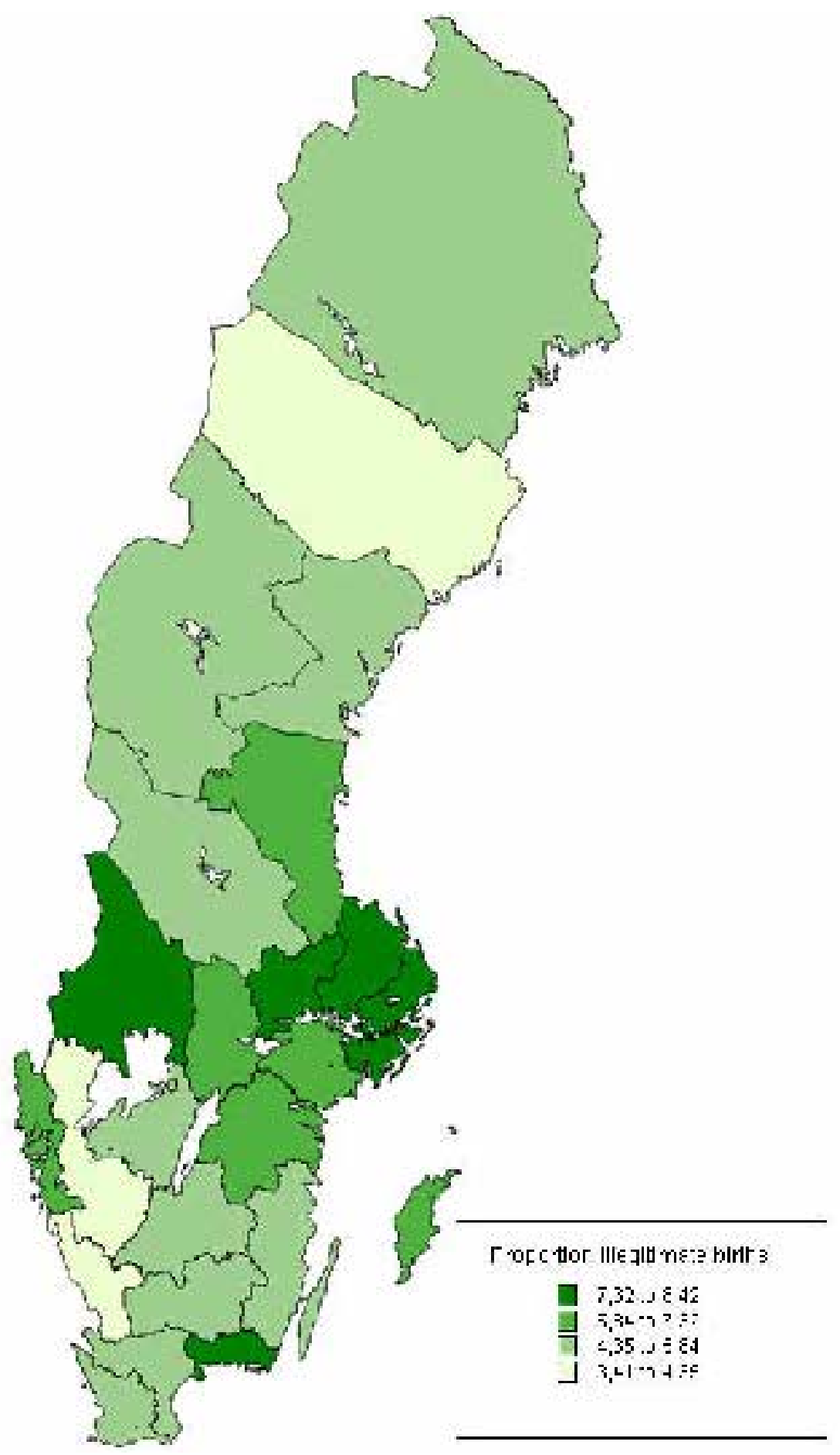

Source: Tabellverket. Provincial statistics. National Archives. 
Map 10. Illegitimate infant mortality in the rural parts of the Swedish provinces, 1901-1910, per 1.000 live births.

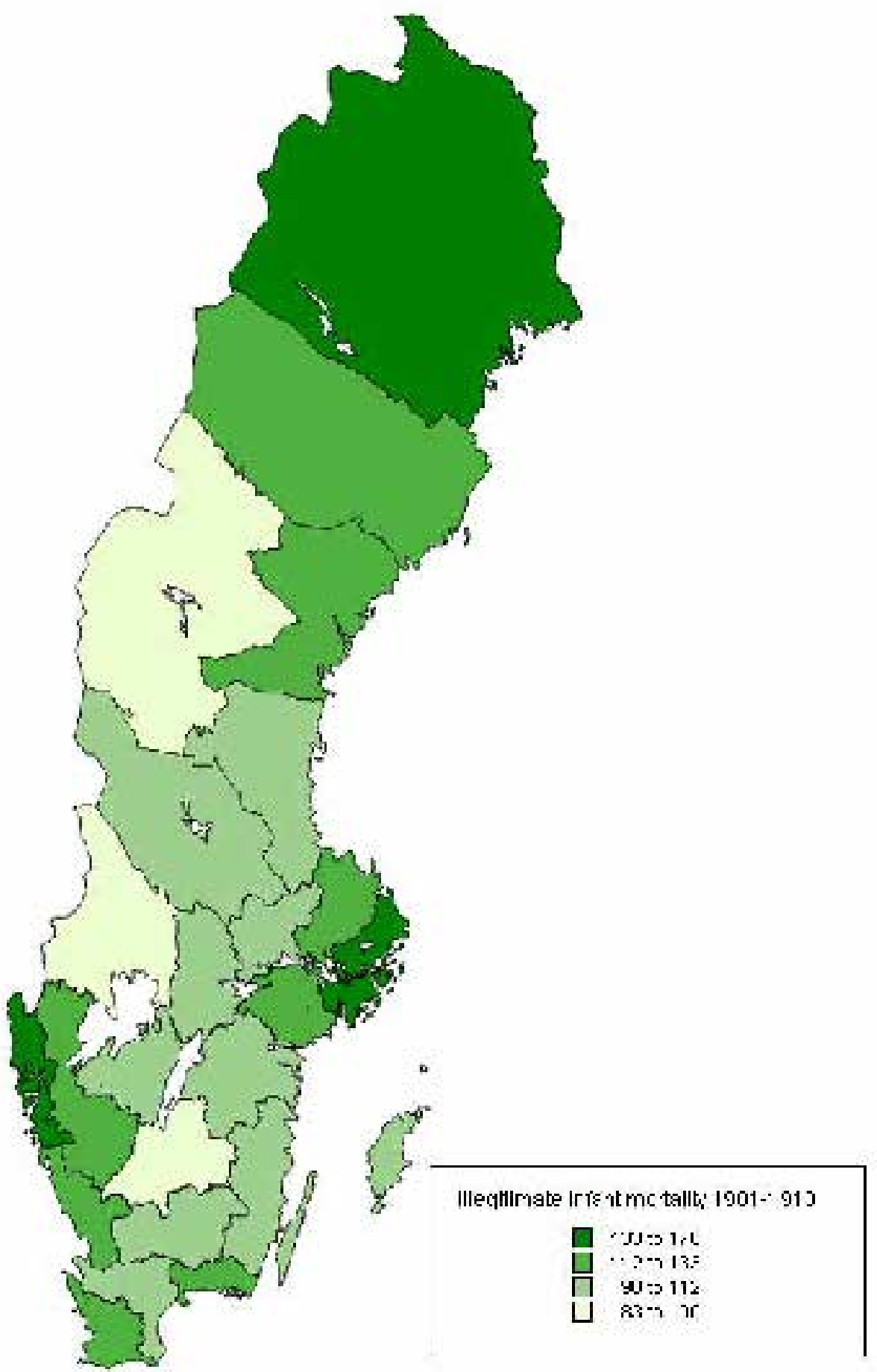

Source: Statistiska Meddelanden Ser A, Band I:4. Utom äktenskapet födda barn (Stockholm, 1914). 
Map 11a. Excess illegitimate infant mortality, Swedish provinces, 1901-1910. Illegitimate infant mortality/legitimate infant mortality* 100 .

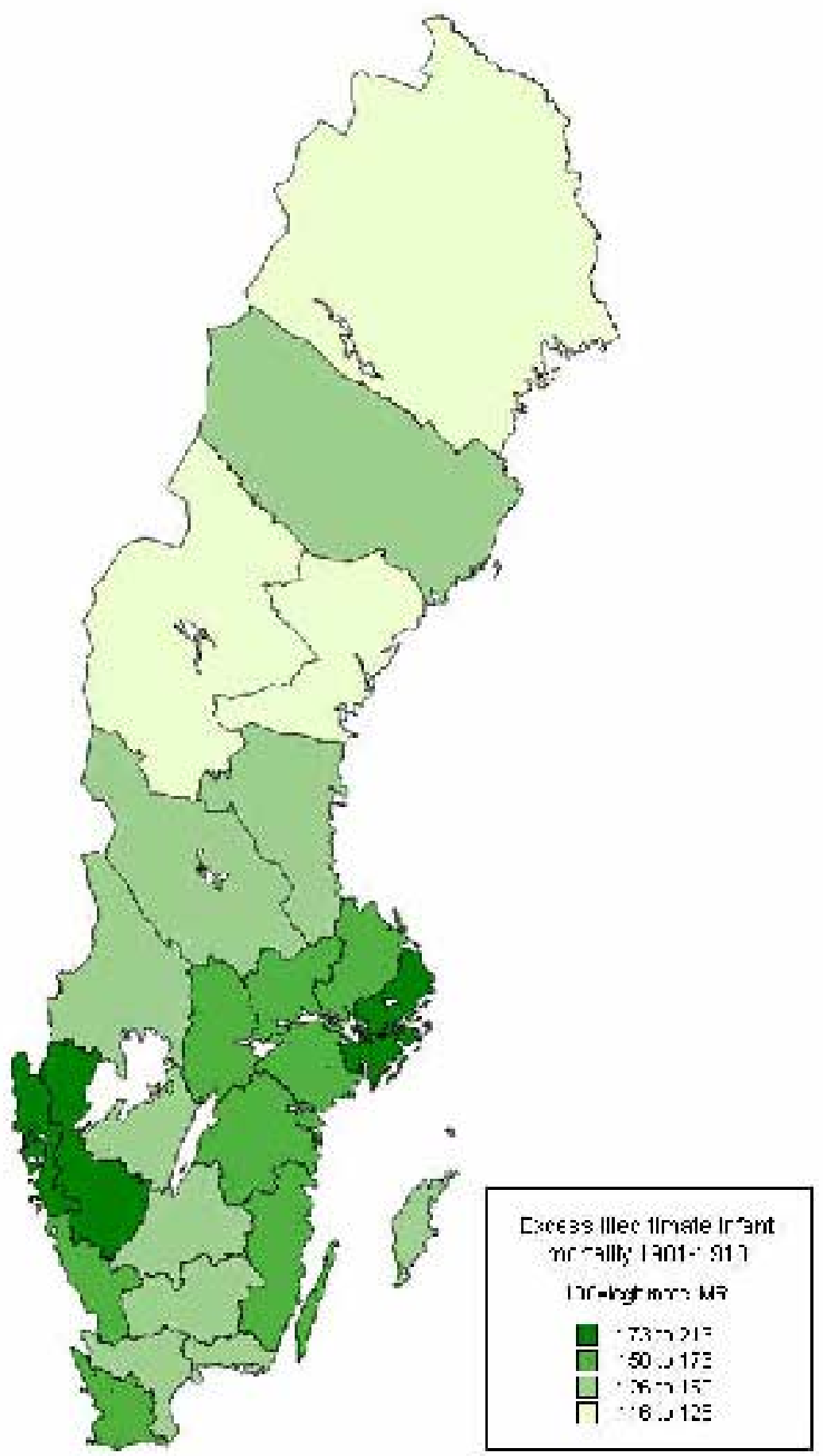

Source: Statistiska Meddelanden Ser A, Band I:4. Utom äktenskapet födda barn (Stockholm, 1914). 
Map 11b. Illegitimacy in Swedish provinces, 1901-1910. Illegitimate births/all births*100.

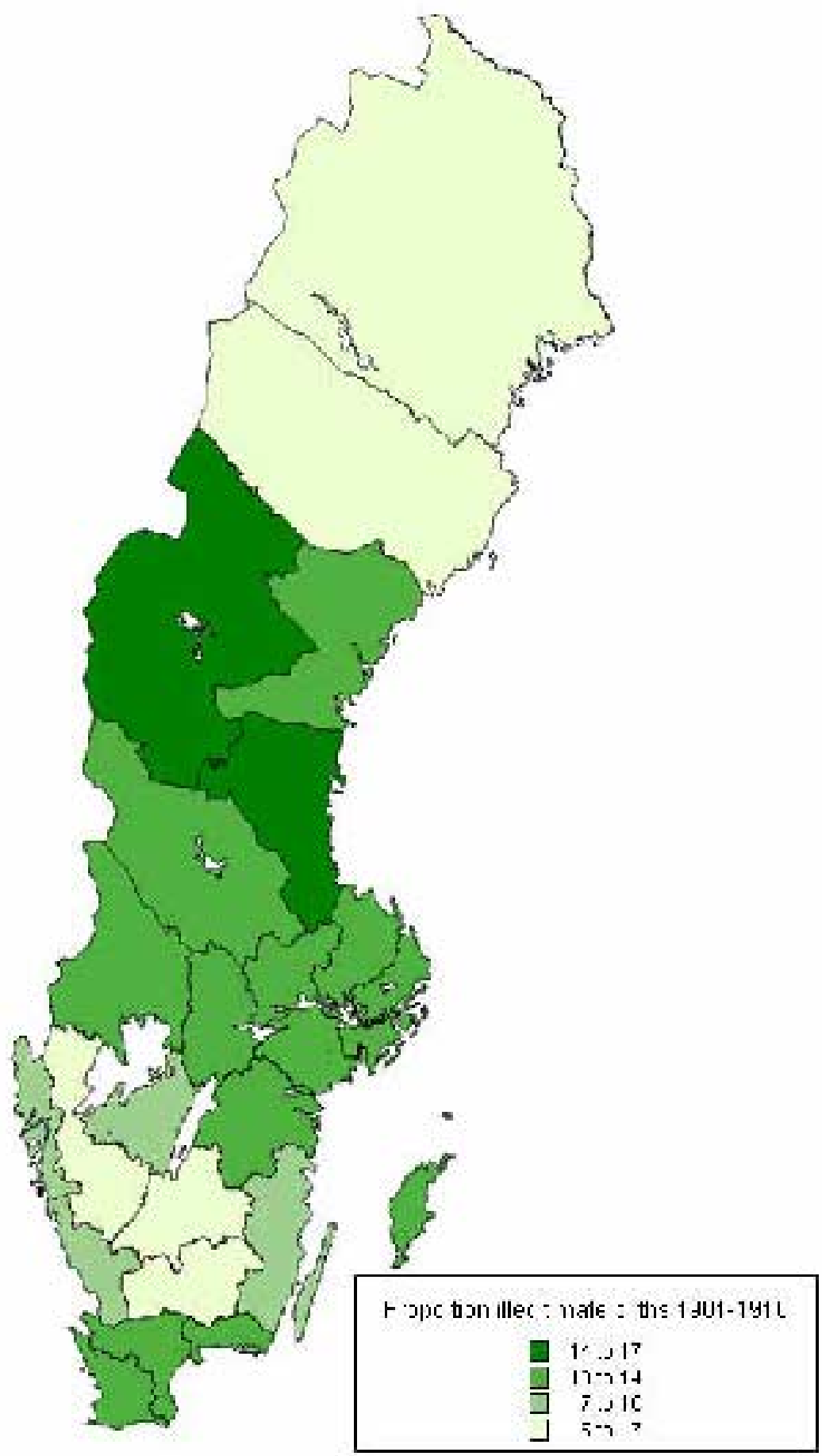

Source: Statistiska Meddelanden Ser A, Band I:4. Utom äktenskapet födda barn (Stockholm, 1914). 
Figure 4. The relationship between rural and urban areas in excess illegitimate infant mortality, Swedish provinces, 1901-1910 (0 = No difference).

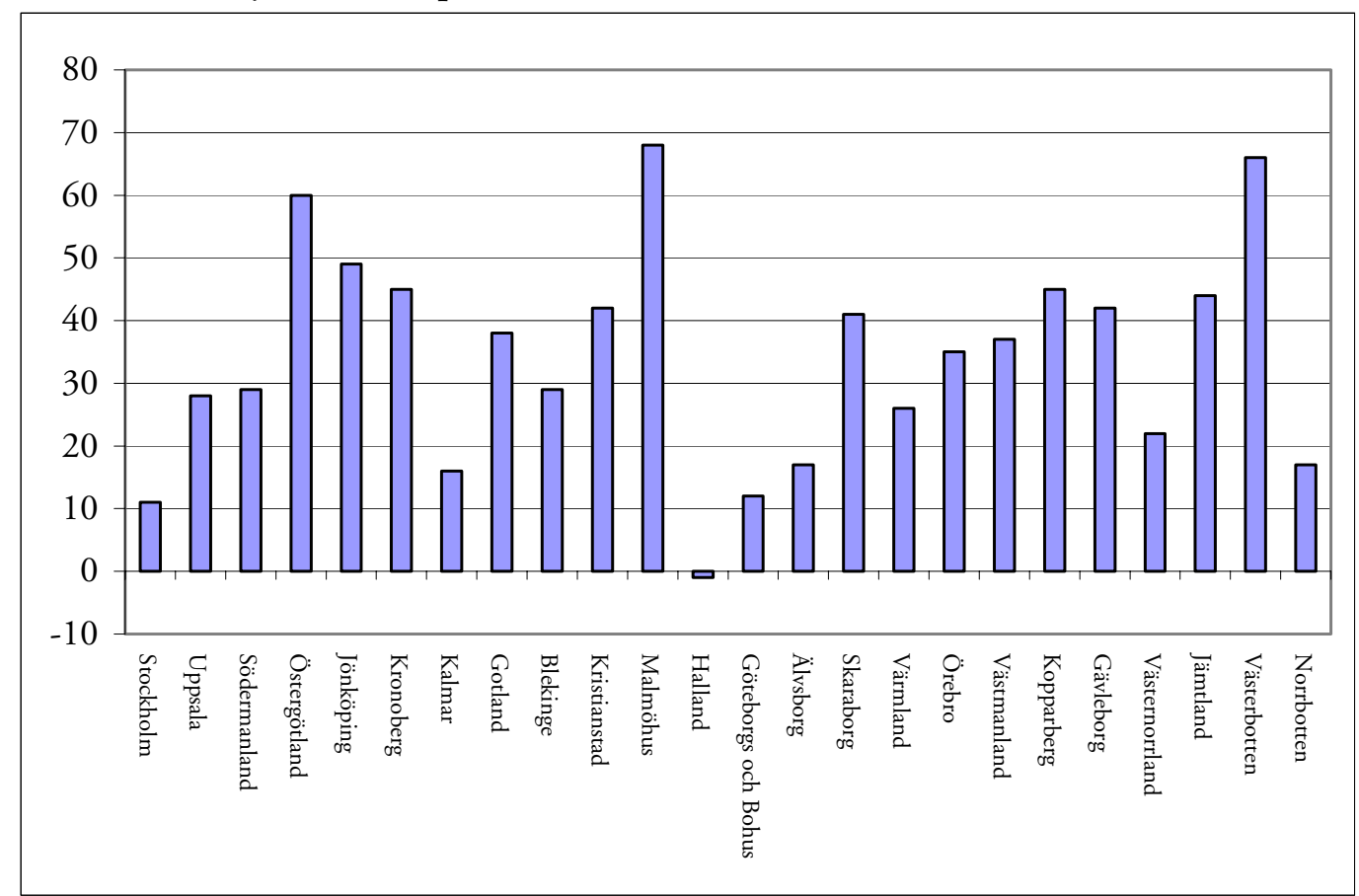

Source: Statistiska Meddelanden Ser A, Band I:4. Utom äktenskapet födda barn (Stockholm, 1914).

illegitimate births in the provinces. For instance, the province of Norrbotten in the north, which had very high illegitimate infant mortality, had a low level of excess illegitimate mortality as well as a low proportion of illegitimate births. In contrast, provinces around Stockholm and on the southeast coast had relatively high levels of illegitimate infant mortality, high levels of excess infant mortality and a high proportion of children born out of wedlock.

As mentioned above, illegitimacy was mainly an urban phenomenon, especially toward the end of the nineteenth century. Excess illegitimate infant mortality was also an urban phenomenon. Figure 4 displays the difference between excess mortality in urban versus rural parts of the Swedish provinces in 1901-1910. Here we find that urban centers, with the exception of the province of Halland, had an average of approximately 35 more illegitimate deaths per 1000 live births compared to rural areas. To conclude, the regional analyses on the provincial level have shown that illegitimacy was a relatively stable phenomenon over time. No direct correlation existed between the proportion of illegitimate births and an excess mortality among children born out of wedlock except in urban areas. However, as in the case of the regional analysis of infant mortality, provincial-level data appear to be too crude to allow any conclusions to be drawn on how illegitimacy and infant mortality interacted. In order to obtain a clearer picture of the mechanisms 
which determine a high infant mortality for illegitimate children, an analysis of 2,569 women who gave birth to illegitimate children in the Sundsvall region has been carried out. The complete reproductive life histories of these women have been reconstructed using the registers of 16 parishes surrounding the town of Sundsvall in the province of Västernorrland. ${ }^{18}$ A control group of 4,529 married women who never experienced an illegitimate birth was also extracted from the same registers. The two groups are matched on age at first birth, social class at first birth, parish at birth of first child and their presence in the parish during the same period. The unwed mothers gave birth to 5,749 children and mothers in the control group to 18,395 children. In all, the analysis includes a total of 24,144 births between 1808 and 1900. The analysis of the town of Sundsvall is restricted to the second half of the nineteenth century. ${ }^{19}$

Women who at some point in time gave birth to illegitimate children were followed from the birth of their first child to their last child or to age 50, or to the period if their histories were somehow truncated. Usually, the illegitimate births were the initial ones in the reproductive history. The study focuses primarily on comparing risks of dying for children born out of wedlock with the legitimate children born later in the same family. The fate of these children, in turn are compared with those from families in which no illegitimate births occurred. The analysis relies on techniques based on collective event histories, such as logistic regression. Each child that died as an infant was followed (together with its mother) until the date of death and compared with those who survived infancy. Each new child in the family, illegitimate or legitimate, formed a new record in the analysis. One problem with the method, however, is that it to some extent disregards the fact that several children are related, and we know that infant mortality is highly family dependent. ${ }^{20}$ But, statistically, it is difficult to include such dependence in this type of analysis. To partially compensate for this, a number of "family" variables relating to the

18 Four of the parishes existed as separate parishes for only shorter periods: Lögdö, Galtström, Lagfors and Svartvik. The four parishes early had foundries, but contained large sawmills during the second half of the nineteenth century. When included in the analyses, however, they are generally treated as part of one of the larger parishes that surrounded them.

19 All the registers in the town before 1860, with the exception of the catechetical examination register, were destroyed in a large fire in 1888. Since the catechetical registers at times fail to include newly born children, they cannot be used for studies of infant and childhood mortality.

20 Anders Brändström, "De kärlekslösa mödrarna" Spädbarnsdödligheten i Sverige under 1800-talet med särskild hänsyn till Nedertorneå (Umeå, 1984); Katherine A. Lynch and Joel B. Greenhouse, "Risk Factors for Infant Mortality in Nineteenth-Century Sweden," Population Studies, 48:1 (1994), 117-133. 
Figure 5a-c. Survival functions for legitimate and illegitimate children in the town of Sundsvall, industrialised parishes and agrarian parishes in the Sundsvall region. First 365 days after birth.

Figure 5 a

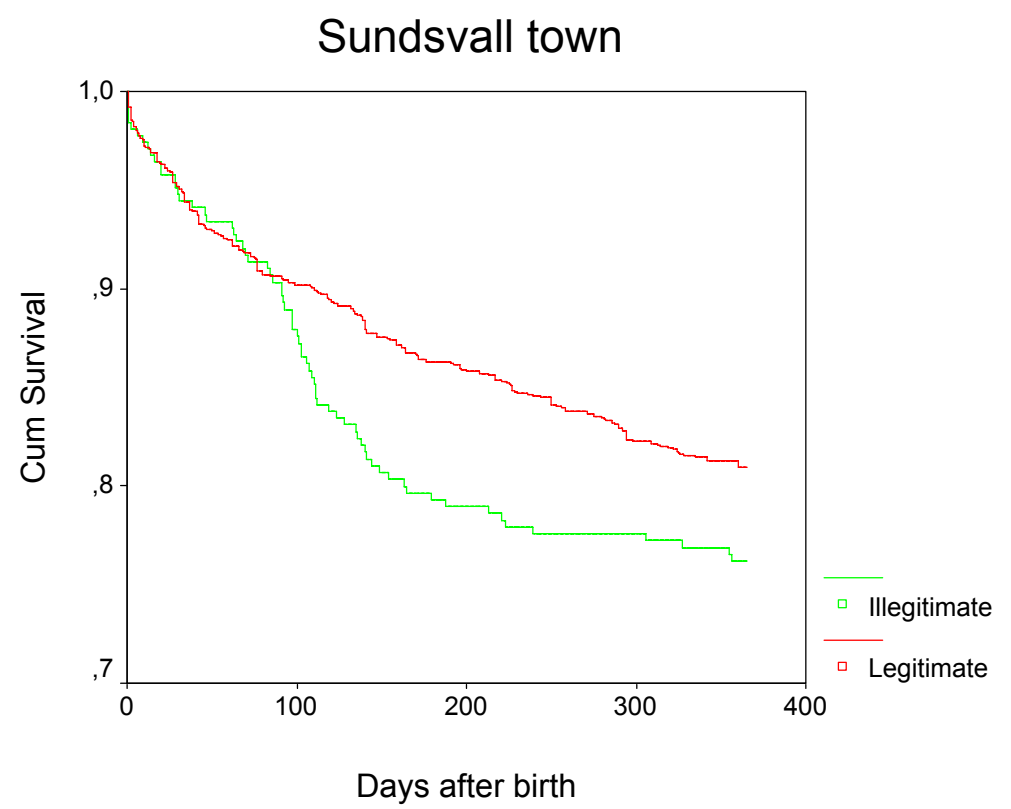

Figure $5 \mathrm{~b}$

Industrialized parishes

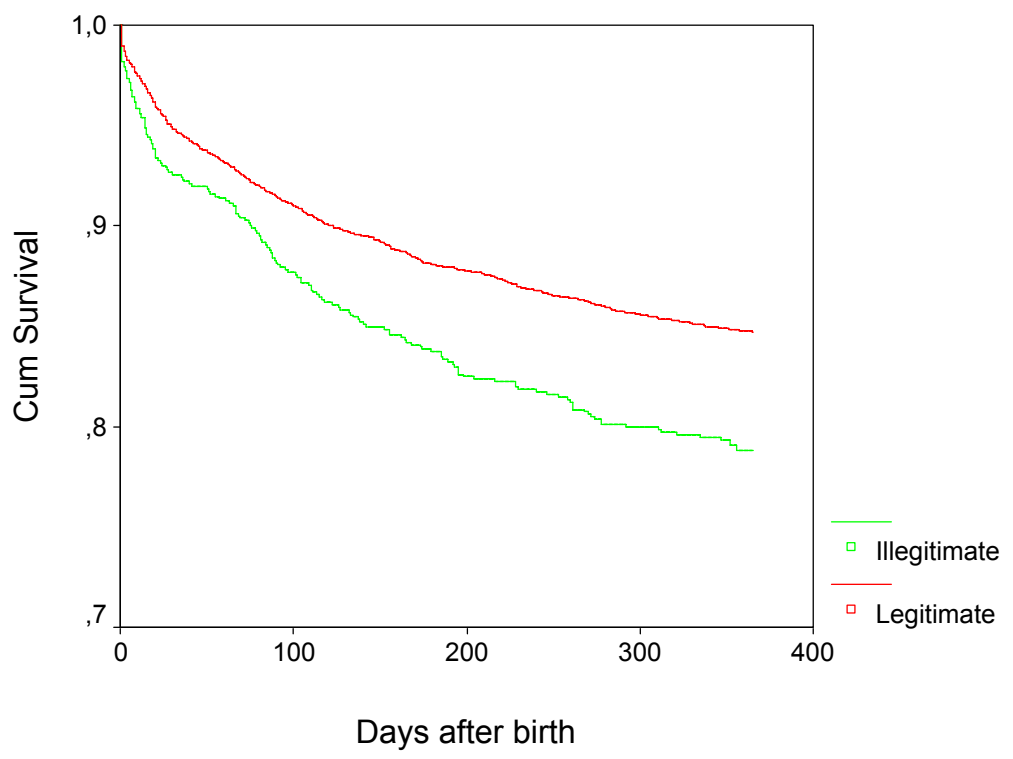


Figure $5 \mathrm{c}$

Agrarian parishes

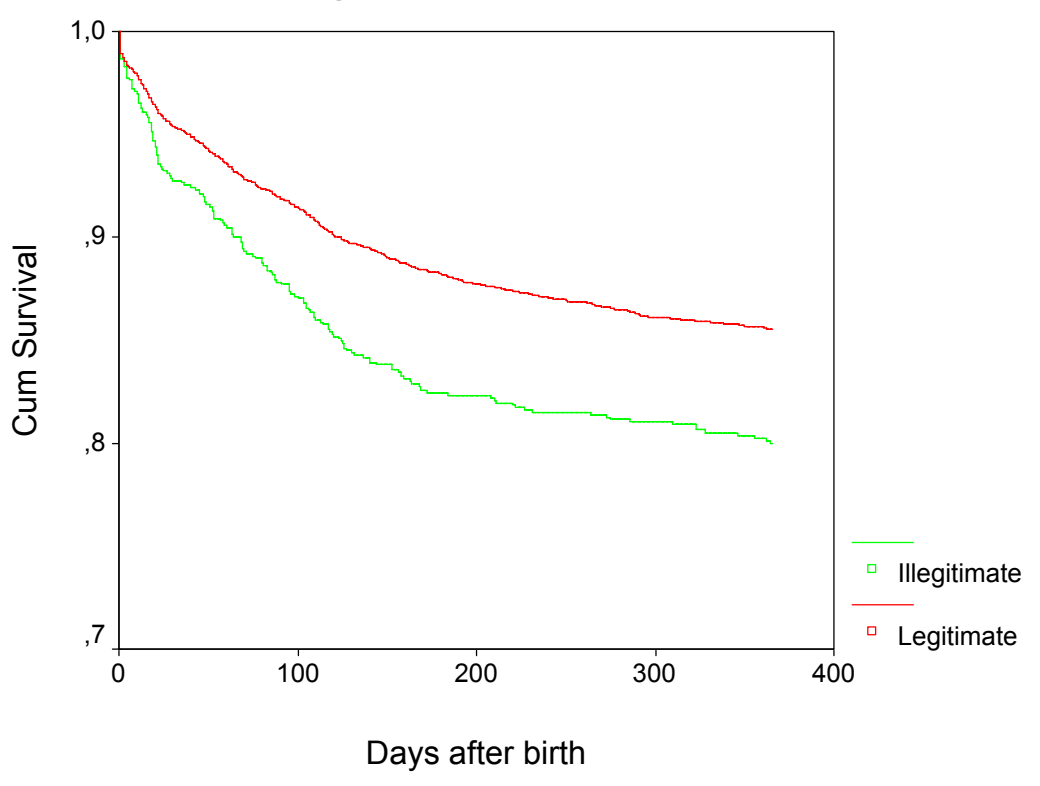

Source: The Demographic Data Base, Umeå University.

complete life history of the mother were attached to every child, such as parity and the total number of legitimate and illegitimate births in the family.

Illegitimate infant mortality was very high in the town of Sundsvall: 200 per thousand during the period $1860-1879$ and 216 during the 1880-1892 period. For children born out of wedlock, when compared to legitimately born children, the increased risk of dying was in the range of 70-80 percent. ${ }^{21}$ Figure 5a-c show the survival function for legitimate and illegitimate children born in three Sundsvall settings: the town of Sundsvall, agricultural parishes and industrial parishes. ${ }^{22}$ In all three cases illegitimate children had a lower rate of survival. Both legitimate and illegitimate children in the town of Sundsvall had lower survival rates compared to children in the other two areas. Approximately 25 percent of the illegitimate children died within a year after birth, while the rate was 20 percent in the other areas. The corresponding figures for legitimate children were 18 percent in the town and 14-15 percent in the industrialized and agricultural parishes. Interestingly, the chances of survival in the less healthy urban environment affected legitimate and

21 Sören Edvinsson, Den osunda staden. Sociala skillnader $i$ dödlighet $i$ 1800-talets Sundsvall (Umeå, 1992), 172.

22 Except for the small iron foundries that were established in some parishes, no real industrialization took place in the region before 1850 . 
illegitimate children equally during the first three months after birth. Only after that age were the illegitimate children in a less favorable position.

A majority of the women in Sundsvall managed to marry despite the fact that they had experienced one or more illegitimate births. In most cases they also managed to marry within their social class - mainly because most of them already belonged to the lowest social strata in society. The chances of survival increased considerably for children born after their mother married. ${ }^{23}$ However, the fact that children born in a complete family had a better chance of surviving infancy compared to their siblings who were born out of wedlock does not necessarily mean that conditions were normalized. The question is whether children born in previously incomplete families survived equally as well as other children in Sundsvall? If this was not the case, that is, if mortality remained at a higher level, it would indicate that even if these women managed to marry, they still lived under conditions which negatively affected the survival of their children. Marriage probably improved many things, but it may not have completely eliminated the negative consequences of their previous reproductive history, that is, they may have found themselves in economic and social circumstances similar to those when they were single mothers.

In Figure 6 the chances of survival are plotted for illegitimate children and their legitimate siblings born in the Sundsvall region (town excluded) after their mothers married. Also included are the survival chances for children from a control group of women with no illegitimate births in their fertility history. These are matched for age, class, parish of origin and time period. The poor survival rates for the illegitimate children are quite obvious in comparison with the fate of their siblings born after their mothers married. Marriage meant that the chances of survival improved to a level equal to that of children from the control group. The two curves are as closely matched as they can possibly be. Illegitimacy in Sundsvall tended to be a life cycle phenomenon, something that happened relatively early in the reproductive career with clear negative consequences. However, the majority of unwed mothers eventually married with the result that their social and economic circumstances improved to a level that would equal other women of their age and class. Similar patterns are found in the agricultural and industrialized parishes. The town of Sundsvall is a special case (Figure 7). In the urban environment children born to women with previous illegitimate births continued to suffer. From approximately the second month after birth their cumulative survival chances decreased. The difference, although not substantial (only 5\%), indicates that the social isolation of such women, often termed marginalized, cannot be completely ruled out as a factor in the urban environment. However, the combined results speak in favor of an

23 Anders Brändström, "Life histories of single parents and illegitimate infants in nineteenth century Sweden," The History of the Family, 1: 2 (1996), 205-226. 
Figure 6. Survival functions for the illegitimate and legitimate children of women with illegitimate children and for children in a control group where women have not given birth to an illegitimate child in industrialized and agrarian parishes in the Sundsvall region. Groups matched for age, class, parish of origin and time period. First 365 days after birth.

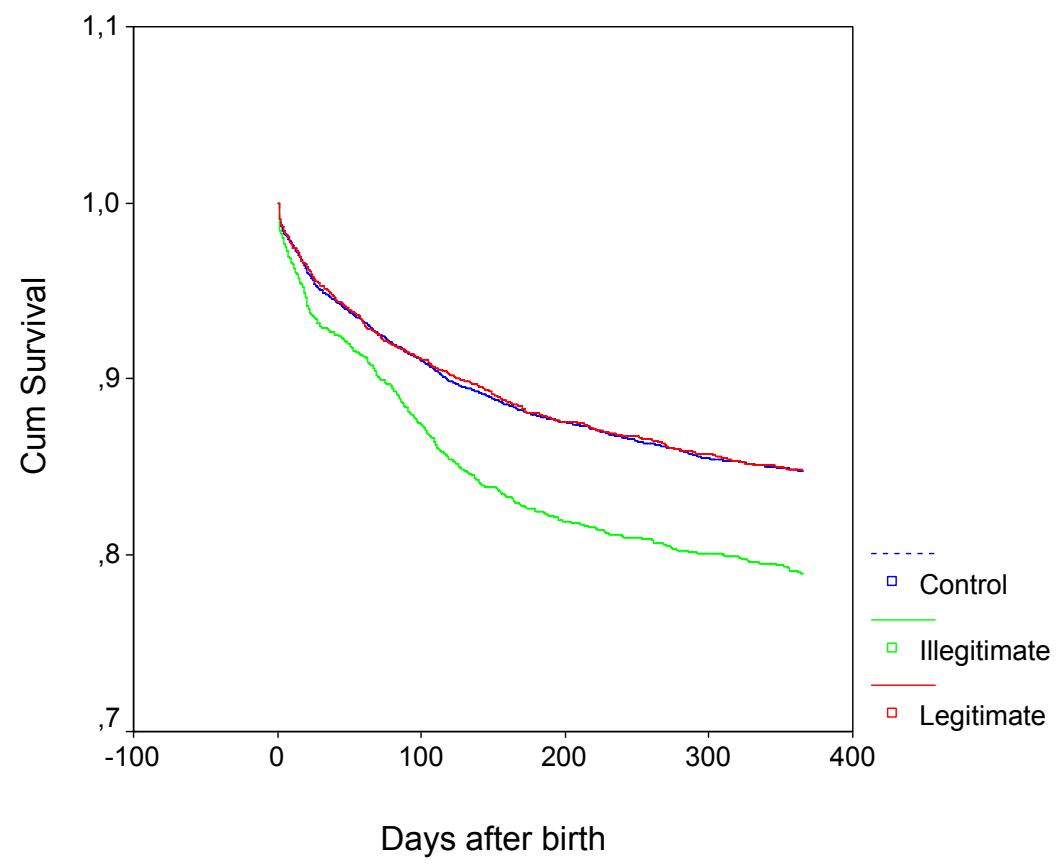

Source: The Demographic Data Base, Umeå University.

interpretation where poverty negatively influenced the chances of survival for children born out of wedlock more than the fact that such women were socially ostracized.

Several factors affect an infant's chances of survival after birth. Such factors may be social or cultural in nature, for example, social status, childcare practices, breastfeeding, personal hygiene, hygiene within the family, or religion. They may be economic and related to family income, female labor, standard of living, nutritional status, or they can be environmental and include such factors as population density and/or sanitation (piped water and sewage systems). Medical factors include the organization of health care, quality of health care, and medical technology. Biological components such as mother's age, parity of the child, birth intervals, disease panorama, virulence and exposure must also be considered. Together they form a very complex web of explanatory factors that both interact and counteract in different historical contexts. Most attempts to model these factors stress the importance of the care and protection an infant receives from its mother and the 
help rendered by family, relatives and friends. ${ }^{24}$ This, in turn, is closely related to the opportunities for such care: that is, does the child live in a family or alone with its mother? Do relatives and friends who can help live nearby? The degree and quality of this care is determined by the above factors. The importance of a complete family for the chances of survival for a child has been underlined in several studies. The lack of one parent had immediate negative effects on the child's chances of survival. If it was the mother, the child faced an almost certain death unless the father soon remarried or other relatives stepped in to help. The loss of the father was less critical, but still affected the child's chances of survival. ${ }^{25}$ Children born out of wedlock normally did not live in complete families and we have noted the negative effects on their chances of survival in the Sundsvall region.

However, even illegitimate children may have had access to a social network which could lend a helping hand to single mothers by providing economic assistance or caring for the child if the mother was required to work. It could be a network of kin or a network of friends or a combination of both. A "sub-culture" within the population with a high degree of tolerance may also have served as a substitute and provided support. The availability of such resources should have had a positive impact on the survival of the child. However, if the available social network did not tolerate such behavior, protecting instead traditional family values, then it may have served rather as a repressive mechanism which would have marginalized these women, worsening their situation. If the hypothesis about marginalization is correct, women with illegitimate children should have moved away from their home parish (here defined as their own parish of birth). If poverty were an important cause, we would expect to find a migratory stream in the other direction.

In the following we shall consider what impact the availability of a kinship network, primarily parents, had for a single mother. Unfortunately, such networks can seldom be measured directly. One means of approaching the problem is to consider survival rates for children born in the home parish of their mother. A check has confirmed that the woman's parents almost always were living in the woman's home parish. Since the mean age at first birth is 23.9 , we may also assume that the parents were still at an age where they could support their daughter in some way.

24 See, for example, Naomi Williams and Chris Galley, "Urban-Rural Differentials in Infant Mortality in Victorian England," Population Studies, 49 (1995), 401-420; Magdalena Bengtsson, Det hotade barnet. Tre generationers spädbarns- och barnadödlighet $i$ 1800-talets Linköping (Linköping, 1996), 60.

25 Increased death rates for children in incomplete families were reported in Orphans and foster-children. A history and crosscultural perspectives, ed. Lars-Göran Tedebrand (Umeå, 1996). 
Figure 7. Survival functions for the illegitimate and legitimate children of women with illegitimate children and for children in a control group where women have not given birth to an illegitimate child in the town of Sundsvall. Groups matched for age, class, parish of origin and time period. First 365 days after birth.

\section{Sundsvall town}

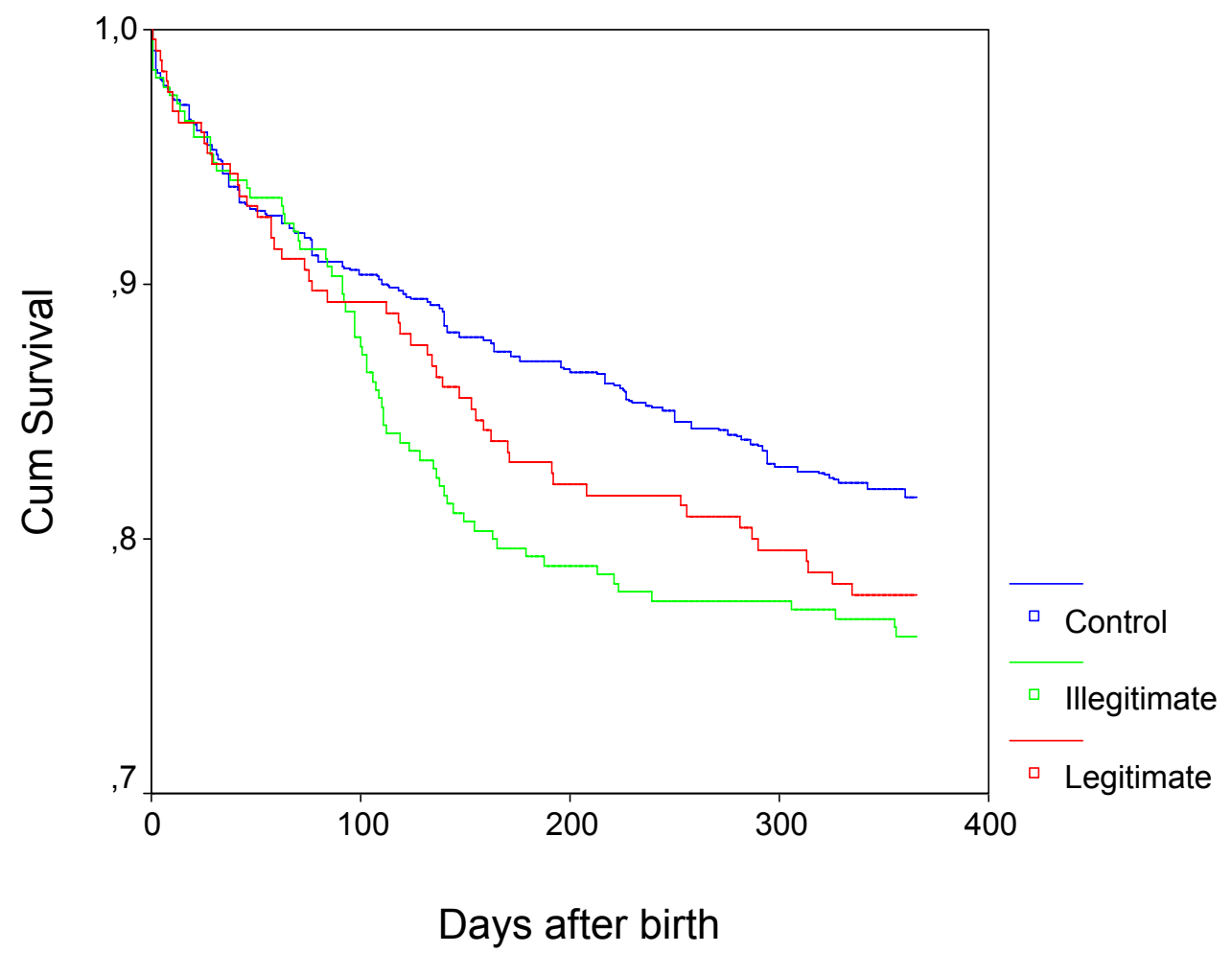

Source: The Demographic Data Base, Umeå University.

Other forms of kin support might also have existed - brothers, sisters, aunts, uncles - but it has not been possible to confirm the presence of such relatives in the available material. As such, we can only measure the theoretical availability of such a network. The fact that parents or other relatives lived in relatively close proximity does not automatically mean that they also gave support.

The results of the analysis are striking and, as can be seen in Figure 8, giving birth in the home parish of the mother had clear negative effects on the child's chances of survival! The difference is not large, only two to three percent, but the pattern is consistent in all three settings in the Sundsvall region - the town, the industrialized parishes and the agrarian parishes. The results do not support the hypothesis that a kin network provides support for unwed mothers. Instead, they suggest that it was more advantageous for an expectant mother to migrate to another parish. It speaks in favor of social stigmatization as a factor in explaining 
the survival of illegitimate children. Relative anonymity seems to have favored an unwed mother in her attempts to give her child proper care. However, we might consider another explanation. The analysis could be picking up the biological effects of mother's age and parity. Early motherhood is more common in the home parish: 70.9 percent of all first illegitimate births in the Sundsvall region took place in the parish where the mother was also born. As her life progressed, the likelihood of migration increased, and the figure was reduced by five percent for each additional illegitimate birth that she experienced.

Using logistic regression analysis allows us to control for such variables as parity and age and to better determine if a "kin network" is significant for an illegitimate infant's chances of survival. A variable called "place" has been created which indicates whether or not the birth took place in the home parish. This variable is entered into the equation together with a set of "biological" explanatory variables or covariates such as mother's age, parity of the child, birth intervals and sex of the child. Two "social" variables are also included in the full model, type of birthplace (i.e., whether the child was born in the town, in an industrialized parish or in an agricultural parish) and the social class of the mother. The dependent variable in the equation is a dummy variable indicating whether the child died as an infant or not. The full model produced the following results (Table 1).

If we first consider the effects of a parish's economic structure, we find that to be born in the town of Sundsvall increased the risk of dying by eight percent (Exp $(B)=1.0853)$. The figure is slightly lower for industrialized parishes when all the other factors are kept constant. To be born in the same parish as the mother increased the risk of dying by 24 percent, confirming the results found in Figure 8. Increasing birth intervals decreased the risk of dying by 31 percent for each step. Mortality was slightly reduced as the mother grew older, but by less than one percent for each age group. The chances of survival were slightly better $(3 \%)$ if the mother came from the working class rather than the middle class in Sundsvall. An increase in illegitimate parity also increased the risk of dying as an infant. Finally, to be born as a male was a slight disadvantage - approximately 12 percent. However, it turned out that only birth interval and parity were significant at the five percent level (boldface type) when the other factors were controlled for. Although giving birth in the home parish increased the risk of dying as an infant by as much as 24 percent, the figure is not statistically significant.

Our conclusion must be that "kin networks," as they are defined here, did not significantly contribute to the chances of surviving infancy for illegitimate children when other factors are controlled for. The same is true for such variables as the parish economy, sex and social class. Several of these factors might be important in explaining differences between illegitimate and legitimate children, but they con- 
Figure 8. Survival function for illegitimate children in the Sundsvall region. Children born in the home parish of the mother and children born in other parishes. First 365 days after birth.

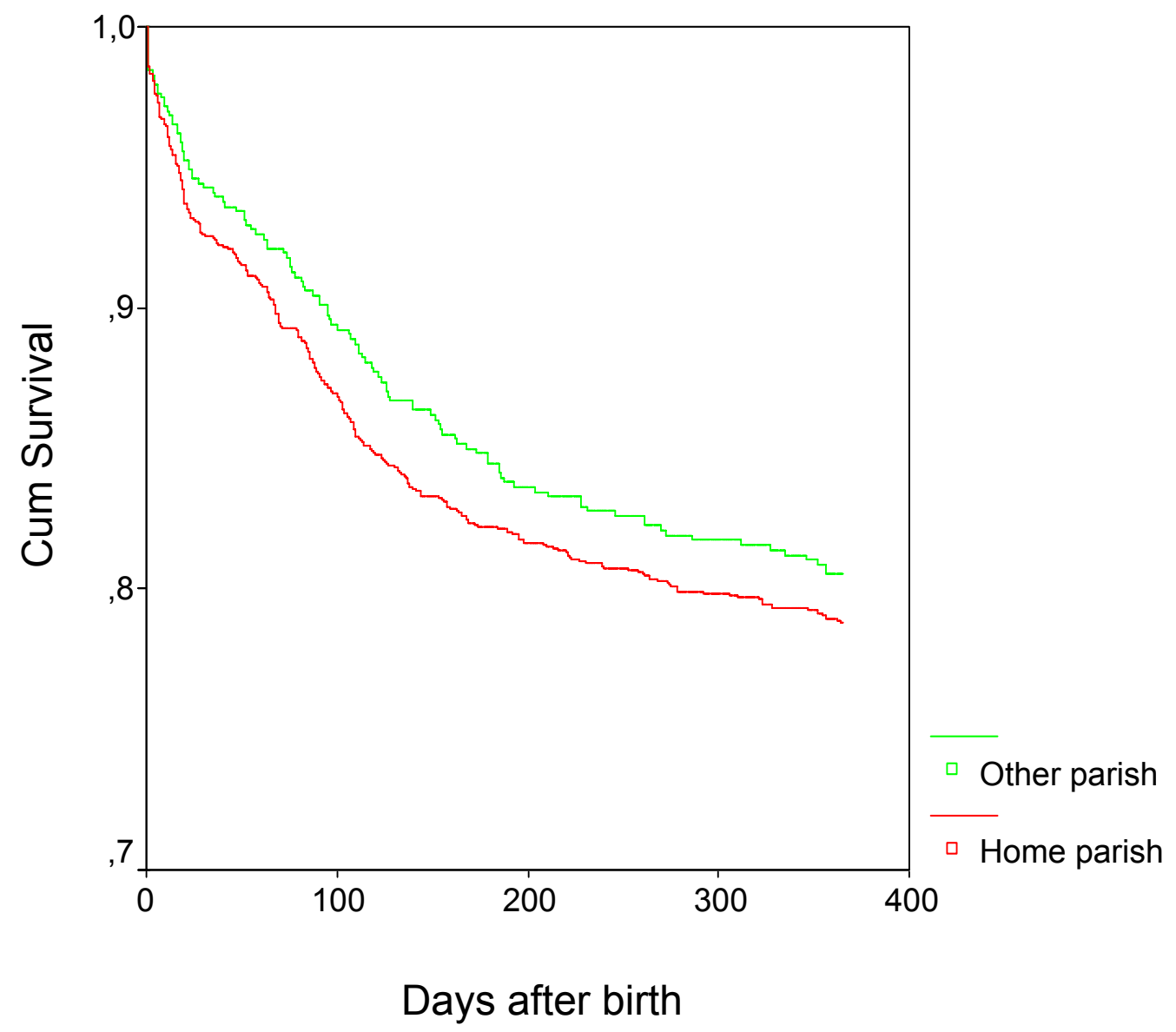

Source: The Demographic Data Base, Umeå University. 
Table 1. Logistic regression analysis of the complete reproductive histories of women who gave birth to an illegitimate child in the Sundsvall region. Dependent variable=infant death. Reference group in parenthesis.

\begin{tabular}{|c|c|c|c|c|c|c|}
\hline \multicolumn{7}{|c|}{ Variables in the Equation } \\
\hline Variable & B & S.E. & Wald. & Df & Sig & $\operatorname{Exp}(B)$ \\
\hline Economy (agricultural) & & & .3901 & 2 & .8228 & \\
\hline Town & .0818 & .1965 & .17338 & 1 & .6772 & 1.0853 \\
\hline Industrial & .0762 & .1299 & .3438 & 1 & .5576 & 1.0792 \\
\hline Place (home) & .2181 & .1366 & 2.5501 & 1 & .1103 & 1.2437 \\
\hline Birth interval $(<2$ years $)$ & -.3646 & .1114 & 10.715 & 1 & .0011 & .6945 \\
\hline Social class (middle) & 0.358 & .1206 & .0880 & 1 & .7667 & 1.0364 \\
\hline Mothers age & -.0084 & .0634 & .0175 & 1 & .8949 & 9917 \\
\hline Parity (6+) & & & 12.840 & 5 & .0249 & \\
\hline 1 & -.9800 & .3984 & 6.0495 & 1 & .0139 & .3753 \\
\hline 2 & -.1283 & .3666 & .1224 & 1 & .7264 & .8796 \\
\hline 3 & -.3881 & .4027 & .9288 & 1 & .3352 & .6784 \\
\hline 4 & -.6983 & .4817 & 2.1021 & 1 & .1471 & .4974 \\
\hline 5 & -.1325 & .5104 & .0674 & 1 & .7951 & .8759 \\
\hline Sex (boy) & -.1279 & .1182 & 1.1702 & 1 & .2794 & .8800 \\
\hline Constant & -5696 & .4750 & 1.4385 & 1 & .2304 & \\
\hline
\end{tabular}

Source: The Demographic Data Base, Umeå University.

Note: B is the estimated coefficient, with standard error S.E. The ratio of B to S.E., squared, equals the Wald statistic. $\operatorname{Exp}(\mathrm{B})$ is the predicted change in odds for a unit increase in the predictor. When $\operatorname{Exp}(B)$ is less than 1 , increasing values of the variable correspond to decreasing odds of the event's occurrence. When $\operatorname{Exp}(\mathrm{B})$ is greater than 1, increasing values of the variable correspond to increasing odds of the event's occurrence.

tribute little towards explaining differences in the chances of survival among illegitimate infants. ${ }^{26}$ Instead, the most important explanatory variables are the number of illegitimate births that the mother experienced and whether or not these births came at short intervals.

To be born out of wedlock severely reduced the chances of survival for an infant, but the primary reason was not marginalization. Even if it is very difficult to separate poverty from marginalization, we would argue that poverty among single

26 This topic was covered more extensively in Anders Brändström, "Life histories of single parents and illegitimate infants in nineteenth century Sweden," The History of the Family, 1:2 (1996), 205-226. 
mothers played a more important role in Sundsvall. Generally, an illegitimate birth was an isolated phenomenon early in the life cycle of the woman. She suffered few consequences on the marriage market and a majority could expect to marry. However, as a single mother there was very little that she could do to improve the situation for her children. It did not make much difference where in the region she lived, unless she remained in the town, in which case her chances of marrying were more limited. Furthermore, it did not matter very much if her parents were nearby. Her children would only benefit if she managed to keep the number of illegitimate births to a minimum with long intervals between births. The only option available that would improve her children's chances of surviving infancy was to marry. Only through marriage could a woman change her life to such an extent that her children would have as good a chance of survival as other infants. Marriage had a positive effect, not only on legitimately born children, but also on illegitimate children when the marriage took place within a year after birth. In this case these children stood a much better chance of surviving infancy.

\section{Concluding Remarks}

The gradual decline of infant mortality in Sweden from the high and fluctuating rates of the latter half of the eighteenth century to the extremely low rates of today has made it difficult to isolate any specific explanatory factor or series of factors. On a superficial level nineteenth century Sweden appears fairly homogeneous with no large racial, religious or ethnic minorities. Geographical diversity is more apparent, ranging from fertile farmland in the south to mountainous areas in the north and a very long coastline. Although regional demographic differences were observed as early as the latter half of nineteenth century, research on infant mortality has mainly focused on either the entire country or specific localities.

An analysis of provincial level data on infant mortality revealed clear regional differences at the beginning of the nineteenth century. High rates of infant mortality are observable in the far north, in the vicinity of the capital, Stockholm, and in a $\mathrm{u}$-shaped band of provinces stretching along the west coast through the southern part of the country to the east coast (Maps 1 and 2). There was no clear relationship with population density during the nineteenth and early twentieth centuries. Urban infant mortality rates were significantly higher than rural rates, but, because the country was so little urbanized during this period, that fact is not reflected in the figures for the provinces. As infant mortality levels dropped, regional patterns changed considerably (Maps 3 and 4). In the 1920s and 1930s a shift in urban-rural differentials took place with urban infant mortality becoming lower than rural infant mortality. After 1950 mortality levels and the difference between the highest 
and lowest rates continued to diminish. The only consistent pattern over a longer period of time is that the northernmost provinces continually registered the highest rates.

The provinces in Sweden, however, are generally so large that highly divergent economic and social structures, as well as distinct cultural areas, are found in one and the same province. A further analysis of the regional differences in infant mortality using parish level data revealed a great deal of diversity. All of the provincial level regions, whether they had high, low, or moderate rates, included smaller areas (larger than a single parish) with divergent levels of infant mortality. In general, the mix of high, moderate, and low is apparent nearly everywhere, a fact missed by earlier research.

Studies of infant mortality in both historical and modern populations have shown that one of the most important factors affecting levels of infant mortality is the manner in which babies were fed. This, in turn, is often associated with economic, social and cultural factors that influenced the method chosen. Regions dominated by, for example, well-to-do peasants could have high, moderate or low levels of infant mortality depending on how local cultural factors such as traditional artificial feeding practices affected breast-feeding. Among the poorer segments of the population economic conditions, requiring the mother's participation in the workforce, could limit the possibility of breast-feeding. On the other hand, women in poverty stricken families may have been forced to breast-feed as alternative food sources were beyond their means. No straightforward association between regional differences in infant mortality and variations in breast-feeding was found, but the data on the prevalence of breast-feeding are limited and ambiguous.

Historically, illegitimate infant mortality has always been higher than legitimate infant mortality. Regional variations in illegitimacy, therefore, must be included in any regional analysis of infant mortality. Illegitimacy increased in Sweden as it did in most of Europe during the nineteenth century, although the reasons for this are still under debate. On a regional level illegitimate infant mortality varied considerably, with the highest rates in the provinces around Stockholm and in the south (Map 8). Illegitimacy was mainly an urban phenomenon in Sweden with rates in towns far exceeding those in the countryside. If we consider excess illegitimate infant mortality for rural Sweden, we find low levels in the north and high levels around Stockholm and sections of the west coast, indicating that illegitimacy may to a large degree have been culturally rooted (Maps 11a-b). Although it is reasonable to assume that in areas with few illegitimate births, illegitimate infant mortality would be high, as unwed mothers would receive little sympathy or help, as well as the converse, no such association was found (Maps 9a-b). The regional analysis on the provincial level indicates that patterns of illegitimacy were relatively stable over time. However, as in the case of the regional analysis of infant mortality, 
provincial-level data appear to be too crude to allow any conclusions to be drawn on how illegitimacy and infant mortality interacted.

Using data on an individual level, certain aspects of the relationship between illegitimacy and infant mortality were analyzed. The reproductive life histories of a little more than eight thousand women who lived in the Sundsvall region (the town of Sundsvall and 16 nearby parishes) during the nineteenth century were extracted from the church records. Of these, approximately 2,500 gave birth to illegitimate children. An analysis of the significance of the presence of social networks, which could provide unwed mothers with support, indicates that the proximity of parents did not improve the chances of survival for children born out of wedlock. Indeed, it would appear that the reverse was true, even though statistically the negative effects were small (Figure 8 and Table 1). Although this suggests that marginalization, in this case ostracizing women with illegitimate children, was important, the various other analyses of the individual level data indicate that poverty among single mothers played a more important role in determining levels of infant mortality in the Sundsvall region (Figures 5-7). Unwed mothers generally were hard put to make ends meet. However, an illegitimate birth was often an isolated phenomenon early in the life cycle. As a single mother, there was little a woman could do to improve the situation for her children except to marry. Most unwed mothers in the region eventually did marry.

It becomes clear from the analyses undertaken in this paper that the systematic study of regional differences can provide new insights on how two of the major factors affecting levels of infant mortality, feeding practices and illegitimacy, interacted as infant mortality declined. Furthermore, it becomes clear that any deeper understanding of the mechanisms behind Sweden's gradual decline in infant mortality requires analysis of families and individuals.

Anders Brändström is Associate Professor and Head of the Demographic Data Base, Umeå University, SE-901 97 Umeå, Sweden.

Sören Edvinsson is Associate Professor at the Demographic Data Base, Umeå University, SE-90197 Umeå, Sweden.

John Rogers is Associate Professor at the Department of History, S:t Larsgatan 2, SE-753 10 Uppsala, Sweden. 